\title{
Greisens associados ao topázio-granito do pluton Água Boa, província estanífera de Pitinga: petrografia e balanço de massa
}

\author{
Gilmara Regina Lima Feio ${ }^{1,2}$, Roberto Dall'Agnol ${ }^{1}$ \& Régis Munhoz Krás Borges ${ }^{1,3}$
}

\begin{abstract}
Resumo Os greisens da área Grota Rica no pluton Água Boa têm como encaixante o biotita-álcali feldspatogranito com topázio. Formam zonas contínuas de até 6 metros de espessura, exibem cor cinza claro a escuro e textura inequigranular fina a grossa. São compostos fundamentalmente por quartzo, siderofilita e topázio, acompanhados por quantidades variáveis de fluorita, zinnwaldita, esfalerita, cassiterita, zircão e anatásio, sendo classificados como quartzo-topázio-siderofilita-greisen, topázio-siderofilita-quartzo-greisen e topázioquartzo-greisen. A evolução hidrotermal no âmbito do pluton Água Boa levou à greisenização do biotita-álcali feldspato-granito com topázio e culminou com a formação de greisens, mineralizados em Sn e, subordinadamente, $\mathrm{Zn}$. Dados geoquímicos, incluindo cálculos de balanço de massas, do topázio-granito e greisens associados revelaram que a greisenização foi um processo essencialmente isovolumétrico que acarretou uma variação de massa de 8 a 13\%. Constatou-se aumento nos conteúdos de $\mathrm{Fe}_{2} \mathrm{O}_{3} \mathrm{t}, \mathrm{S}, \mathrm{F}, \mathrm{Zn}, \mathrm{Cu}, \mathrm{Sn}, \mathrm{Pb}, \mathrm{Ta}, \mathrm{Rb}$ e $\mathrm{U}$, redução de $\mathrm{Na}_{2} \mathrm{O}, \mathrm{K}_{2} \mathrm{O}, \mathrm{MgO}, \mathrm{CO}_{2}, \mathrm{Ba}$ e $\mathrm{Sr}$ e baixa mobilidade de $\mathrm{SiO}_{2}, \mathrm{TiO}_{2}, \mathrm{Al}_{2} \mathrm{O}_{3}$ e CaO. Os elementos terras raras (ETR) revelaram em geral pouca mobilidade e forneceram padrões muito similares aos dos granitos, observando-se apenas um ligeiro empobrecimento no quartzo-topázio-siderofilita greisen. O processo de greisenização estudado é similar ao observado em greisens da área Guinho-Baixão da Província Pitinga.
\end{abstract}

Palavras-chave: Balanço de massa, greisens, topázio-granito, Pitinga, Cráton Amazônico.

Abstract Greisen associate with the Água Boa topaz-granite, Pitinga tin province: petrography and mass balance. Topaz-bearing biotite alkali feldspar granite is the host rock of the greisen of the Grota Rica area in the Água Boa pluton. The greisen are inequigranular light to dark grey, medium- to coarse-grained rocks and occur as continuous zones up to 6 meters thick, They are composed essentially of quartz, siderophyllite and topaz, with additional variable amounts of fluorite, zinnwaldite, sphalerite, cassiterite, zircon, anatase, monazite, galena, pyrite, chalcopyrite, and native bismuth, being classified as quartz topaz siderophyllite greisen, topaz siderophyllite quartz greisen and topaz quartz greisen. The greisenization of the topaz-bearing biotite alkali feldspar granite culminated in the formation of greisen and quartz veins, the main hosts for Snand, subordinate, Zn-mineralization. Geochemical data, including mass balance calculations, indicate that greisenization processes took place without significant changes in volume, but with a mass variation of 8 to $13 \%$ compared to the original granite. These processes resulted in significant gain of $\mathrm{Fe}_{2} \mathrm{O}_{3} \mathrm{t}, \mathrm{S}, \mathrm{F}, \mathrm{Zn}, \mathrm{Cu}, \mathrm{Sn}$, $\mathrm{Pb}, \mathrm{Ta}, \mathrm{Rb}$, and $\mathrm{U}$ contents and loss of $\mathrm{Na}_{2} \mathrm{O}, \mathrm{K}_{2} \mathrm{O}, \mathrm{MgO}, \mathrm{CO}_{2}, \mathrm{Ba}$, and $\mathrm{Sr}$, while $\mathrm{SiO}_{2}, \mathrm{TiO}_{2}, \mathrm{Al}_{2} \mathrm{O}_{3}$ and $\mathrm{CaO}$ showed low mobility. The rare earth elements reveal little mobility and they patterns are similar to those of the granite, except for the quartz-topaz-siderophyllite-greisen that show slightly lower REE contents compared to the granite. The greisenization process is similar to that described in the Guinho-Baixão greisen area of the Pitinga province.

Keywords: Mass balance, greisen, topaz granite, Pitinga, Amazonian craton.

INTRODUÇÃO Greisens foram definidos por Shcherba (1970) como rochas metassomáticas, cuja origem está intimamente associada a soluções residuais extremamente ácidas oriundas de fusões graníticas evoluídas.

A greisenização é o processo que origina os greisens, sendo a remobilização de sílica e alumina da rocha hospedeira a sua principal característica. Os greisens ocorrem associados a granitos muito evoluídos e seu modo típico de ocorrência é ao longo de fraturas e veios, normalmente nas bordas ou zonas de contato de plutons graníticos. Acumulações de $\mathrm{Sn}, \mathrm{W}, \mathrm{Mo}, \mathrm{Ta}, \mathrm{Nb}$, ETR e Zr geram importantes depósitos, distribuídos no mundo todo, mas principalmente na Inglaterra, Sudeste da Ásia, Estados Unidos e Brasil.

No Brasil, em especial na Amazônia, a greisenização é um dos principais processos responsáveis pela concentração de metais em três províncias estaníferas proterozóicas: Província Estanífera de Rondônia (Leite Júnior 2002), Província Estanífera do Sul do

1 - Grupo de Pesquisa Petrologia de Granitóides, Universidade Federal do Pará, Belém, Pará, Brasil. E-mail: gilmara@ufpa.br, robdal@ ufpa.br,munhoz@ufpa.br

2 - Programa de Pós-graduação em Geologia e Geoquímica (PPGG-UFPA)

3 - Colegiado de Geologia, Universidade Federal do Pará, campus Marabá 
Pará (Teixeira 1999) e Província Estanífera de Pitinga (Borges 1997, 2002; Costi et al. 2002, 2005). Apesar da importância dessas províncias ainda são restritos os estudos detalhados sobre a evolução dos greisens e os processos hidrotermais responsáveis por sua geração. Com este intuito, serão discutidos neste artigo os resultados de estudos petrográficos e geoquímicos de greisens associados ao topázio-granito da área Grota Rica, fácies mais evoluída do pluton Água Boa - Província Estanífera de Pitinga, bem como uma discussão sobre as transformações químicas que afetaram os granitos e geraram os greisens.

CONTEXTO GEOLÓGICO REGIONAL A Província Estanífera de Pitinga está situada a $300 \mathrm{~km}$ a norte da cidade de Manaus no estado do Amazonas, Brasil (Fig. 1a). Enquadra-se tectonicamente na porção sul do Escudo das Guianas, parte integrante do Cráton Amazônico (Almeida et al. 1981, Gibbs \& Barron 1983). Nos modelos de províncias tectono-geocronológicas, a região situa-se no limite entre as províncias Amazônia Central e Ventuari-Tapajós (Tassinari \& Macambira 2004).

Os granitóides da Suíte Intrusiva Água Branca são as rochas mais antigas da região de Pitinga, forneceram idades entre 1,89-1,90 Ga (Almeida 2006; Valério 2006) e estão em contato com rochas vulcânicas do Grupo Iricoumé com idade de 1,88 Ga (Costi et al. 2000, Ferron 2006). Na região de Pitinga (Fig. 1b), as rochas dessa associação vulcânica possuem diversos corpos graníticos relacionados (granitos Simão, Rastro, Bom Futuro e Alto Pitinga), que forneceram idades $\mathrm{Pb}$ $\mathrm{Pb}$ em zircão similares às das rochas do Grupo Iricoumé e foram interpretados como equivalentes plutônicos dessas rochas e agrupados sob a denominação de Suíte Mapuera (Ferron et al. 2006, Ferron 2006).

Dados isotópicos em rochas dos plutons Madeira, Água Boa e Europa mostraram que esses são significativamente mais jovens do que as suas encaixantes vulcânicas, com idades em torno de 1,83-1,82 Ga (Costi et al. 2000, Lenharo 1998).

Tais granitos são seguidos na estratigrafia por sedimentos flúvio-eólicos continentais, rochas piroclásticas da Formação Urupi (Veiga Jr. et al. inédito), por um conjunto de sills toleiíticos e diques da Formação Quarenta Ilhas, de idade U-Pb de $1790 \pm 7 \mathrm{Ma}$ (SHRIMP em badeleíta; Santos et al. 2002).

$\mathrm{O}$ último evento identificado na província corresponde ao magmatismo básico alcalino potássico da Formação Seringa, do Mesoproterozóico, com idade de $1079 \pm 18$ e $1090 \pm 13$ Ma (K-Ar em hornblenda; Araújo Neto \& Moreira 1976).

GEOLOGIA LOCAL Os plutons Madeira e Água Boa apresentam mineralização de Sn (Horbe et al. 1985, 1991; Daoud \& Antonietto Jr. 1985; Daoud 1988; Borges 1997; Costi et al. 2002), sendo que no pluton Madeira a mineralização de Sn é magmática e ocorre disseminada na fácies albita-granito, enquanto no pluton Água Boa a mineralização é hidrotermal e está as- sociada com greisens e epissienitos sódicos.

O pluton Água Boa tem forma aproximadamente elíptica, alongada segundo a direção NE-SW e é intrusivo em rochas vulcânicas e piroclásticas do grupo Iricoumé (Fig. 1c). É constituído por quatro fácies, sendo a mais precoce um biotita-álcali feldspato granito de granulação média a grossa, que ocorre ao longo das bordas noroeste e sudeste do batólito. Mostra fenocristais esparsos de feldspato potássico com coroas de plagioclásio (textura rapakivi), sendo, em função disso, designado historicamente como granito rapakivi (Daoud \& Antonietto Jr. 1985). É composto por feldspato potássico pertítico, oligoclásio e quartzo, com proporções subordinadas de biotita e anfibólio e acessórias de fluorita, zircão, opacos e apatita. A fácies colocada a seguir é um biotita-granito porfirítico, com fenocristais de feldspato potássico euédricos e matriz de granulação fina, que forma faixas alongadas e estreitas, dispostas próximo às bordas do corpo (Fig. 1c). É hololeucocrático e composto essencialmente por feldspato potássico pertítico, quartzo e plagioclásio, com baixas proporções de biotita, anfibólio, fluorita e opacos. A seguir, deu-se a colocação da fácies de maior extensão superficial no corpo, que é um biotita-álcali feldspato granito médio a grosso, composto por mesopertita, quartzo e raro plagioclásio. A fácies mais tardia é representada por um topázio-granito seriado a porfirítico, situado em zona alongada na porção central do corpo (Lenharo 1998). É composto por fenocristais de quartzo e feldspato potássico em matriz de granulação média. Os máficos são representados por biotita e os acessórios por topázio, zircão, fluorita e opacos.

A mineralização hidrotermal de Sn no pluton Água Boa ocorre em: (1) quartzo-greisens com cassiterita, alojados ao longo de fraturas que cortam o biotita-álcali feldspato granito; (2) em siderofilita-topáziogreisens e clorita-fengita-greisens, desenvolvidos na fácies granito rapakivi, próximo ao seu contato com as rochas vulcânicas encaixantes (Borges 1997); (3) em corpos lenticulares de epissienitos sódicos e siderofilita-greisens, enriquecidos em $\mathrm{Sn}$, formados em zonas metassomaticamente alteradas a partir da fácies biotitagranito (Costi et al. 2002, Feio inédito); (4) em topáziosiderofilita-greisens e leucogranitos pegmatíticos albitizados associados ao topázio-granito.

\section{ASPECTOS GERAIS DAS ROCHAS DA ZONA HIDROTERMALIZADA DA ÁREA DE GROTA}

RICA A área Grota Rica está localizada na porção centro-oeste do pluton Água Boa (Fig. 1c). A zona hidrotermalizada foi identificada nos trabalhos de prospecção da empresa Taboca pela ocorrência em superfície de greisens, bem como de depósitos secundários de cassiterita nas proximidades. Visando uma melhor avaliação dos depósitos primários, foi planejada uma malha de sondagem, abrangendo diversos furos, direcionados para a zona hidrotermalizada onde ocorrem os greisens. Dentre os furos de sondagem executados, cujos testemunhos foram todos examinados e amostrados, foi selecionado para estudo detalhado o furo F06Gr 


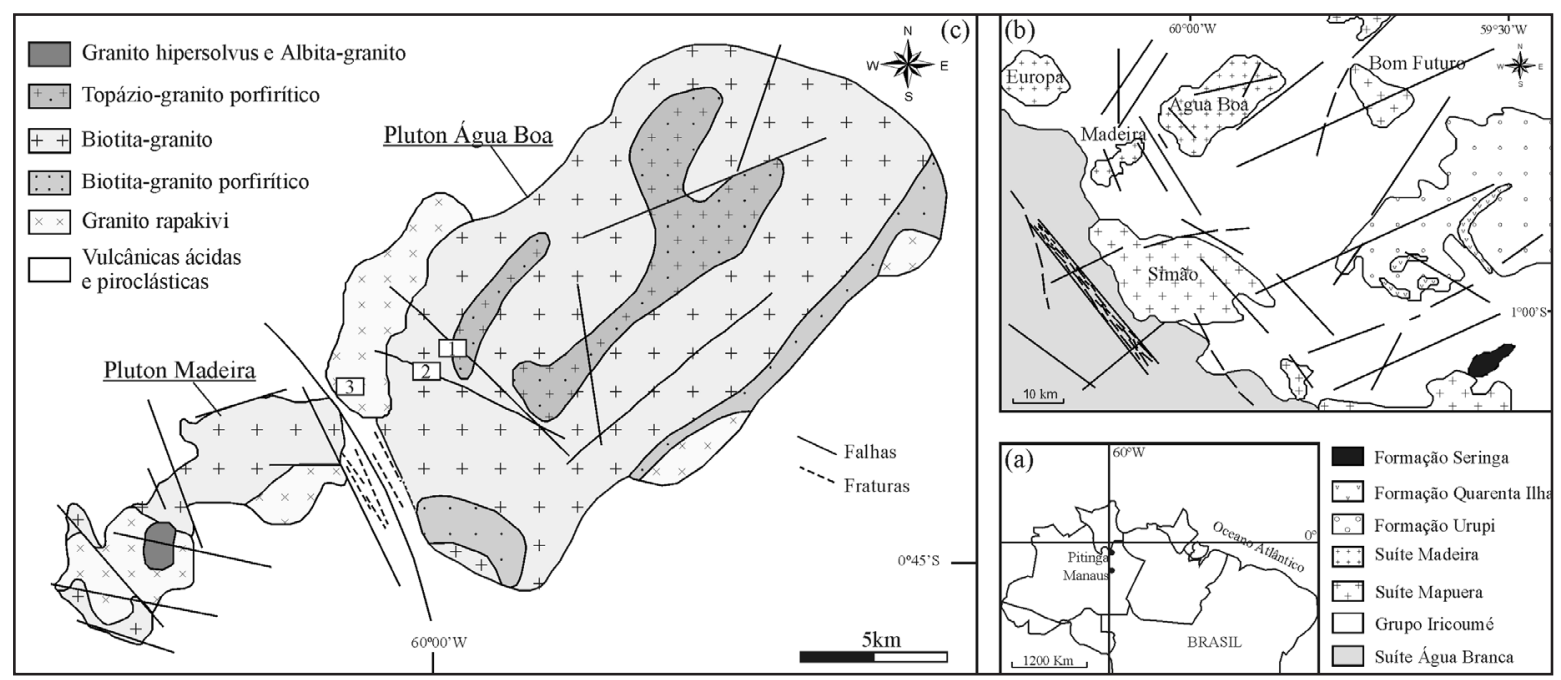

Figura 1 - Mapa Geológico dos granitos Madeira e Água Boa, destacando as áreas de ocorrência dos greisens. (a) Localização da mina Pitinga; (b) Mapa geológico simplificado da região de Pitinga, com distribuição dos granitos das Suites Madeira e Mapuera (Costi et al. 2000, Ferron 2006); (c) Mapa geológico dos granitos Madeira e Água Boa. Os números de 1 a 3 indicam a localização de ocorrências de rochas hidrotermalizadas (Feio inédito, Costi et al. 2005): 1- Greisens associados ao topázio-granito (este estudo), 2- Greisens e epissienitos sódicos associados ao biotita-granito (Costi et al. 2002), 3- Greisens e epsissienito potássico associados ao granito rapakivi (Borges 1997, 2002).

por conter a zona hidrotermalizada mais expressiva. A figura 2 mostra a distribuição dos diferentes litotipos encontrados ao longo do furo F06Gr.

A fácies granítica encaixante dos greisens é o biotita-álcali feldspato granito com topázio, genericamente denominado de topázio-granito. Apresenta coloração acinzentada a rosada e variações texturais, distinguindo-se granito de textura seriada e granito porfirítico, este dominante no intervalo de 79,60-86,60 m. Leucogranitos pegmatíticos, portadores de cassiterita e levemente albitizados, ocorrem na transição entre o granito e os greisens na profundidade de $43 \mathrm{~m}$ do perfil, enquanto que granito albitizado de coloração rosada, resultante de alteração sódica, é encontrado no intervalo compreendido entre 73,22-79,60 m do perfil.

Os greisens são rochas de cor preta a cinza médio, ocorrendo ao longo de fraturas no intervalo 24-73 $\mathrm{m}$ do perfil. A zona greisenizada principal (profundidade 54-60 m) exibe um zoneamento dado por: (1) topázio-siderofilita-quartzo-greisen na zona central; (2) quartzo-topázio-siderofilita-greisen próximo ao contato com granito greisenizado; (3) granito greisenizado transicionando, tanto no contato superior quanto inferior, para biotita-álcali feldspato-granito com topázio. Tais rochas são cortadas por veios de quartzo com esfalerita. Nos contatos com os granitos greisenizados, observa-se substituição do feldspato alcalino e mica marrom por topázio e siderofilita.

\section{PETROGRAFIA}

Composições modais do biotita-álcali feldspato granito com topázio As composições modais, em percentagem, de amostras do biotita-álcali feldspato grani- to com topázio encaixante do greisen são fornecidas na tabela 1. Nela constam as amostras de granito mais preservado e de granito algo albitizado, não estando incluídas as amostras mais intensamente alteradas, devido às proporções das fases minerais presentes em tais rochas terem sido significativamente modificadas e não representarem a composição modal original do granito.

O diagrama Q-A-P (Fig. 3, campos segundo Streckeisen 1976) mostra que, apesar das diferenças texturais, todas as amostras se situam no campo do álcali feldspato-granito e exibem características hipersolvus (Tuttle \& Bowen 1958). A amostra F06Gr/77,46, que é um granito albitizado, exibe conteúdo modal máximo de fengita e baixo de quartzo (Fig. 3, Tab. 1).

$\mathrm{Na}$ confecção do digrama Q-(A+P)-M'(Fig. 3), M' foi considerado como sendo o somatório de minerais máficos (siderofilita, zircão, opacos, anatásio e clorita). O diagrama revela que tais granitos são rochas hololeucrocráticas a leucocráticas com conteúdo modal de máficos entre 1,6 e 8,8\%.

\section{Biotita-álcali feldspato granito com topázio seriado}

O biotita-álcali feldspato granito apresenta coloração rosada a acinzentada e textura seriada média a fina. É composto fundamentalmente de feldspato alcalino pertítico subédrico a anédrico $(<3 \mathrm{~mm})$ e quartzo subédrico a anédrico $(0,4-3 \mathrm{~mm})$. Raros cristais euédricos de albita ocorrem inclusos em feldspato potássico e quartzo, porém próximos das bordas dos cristais (Fig. 4a). A biotita $(\sim 0,5 \mathrm{~mm})$ é da variedade annita transicionando a siderofilita, mostra pleocroísmo de marromavermelhado a amarelo-pálido, e forma agregados ou grãos individuais subédricos, intersticiais aos cristais 


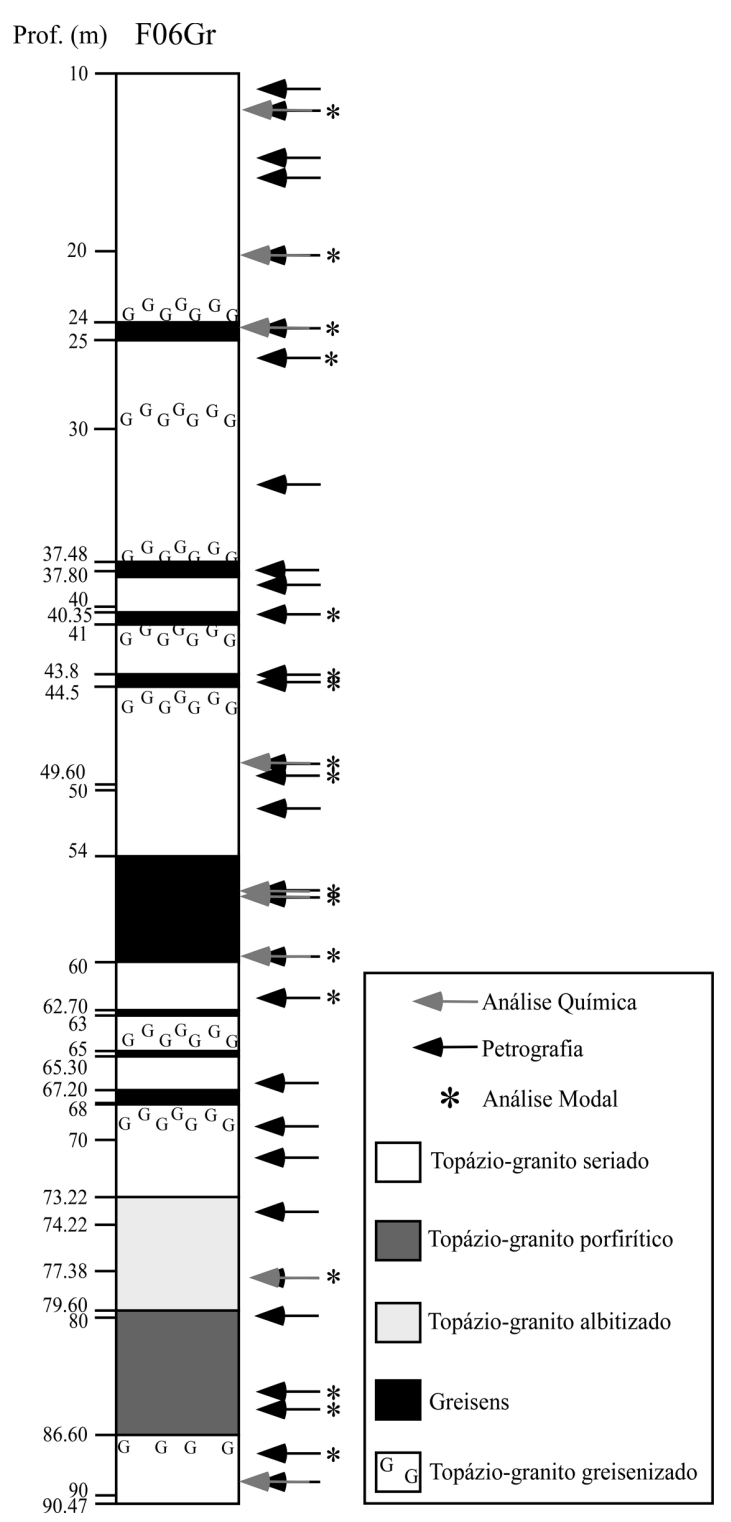

Figura 2 - Perfil vertical do furo F06Gr da malha de sondagem Grota Rica, representativo da zona greisenizada encaixada em biotitaálcali feldspato-granito com topázio.

de quartzo e feldspato alcalino. O topázio magmático ocorre como cristais subédricos a euédricos de granulação fina $(<0,8 \mathrm{~mm})$, ora intersticiais aos cristais de feldspato alcalino e quartzo (Fig. 4b), ora entremeados aos mesmos. Os minerais acessórios são zircão, rutilo e ferro-columbita.

Biotita-álcali feldspato granito com topázio porfirítico O biotita-álcali feldspato-granito com topázio porfirítico apresenta coloração rosada. É composto por fenocristais de granulação grossa de quartzo e feldspato pertítico imersos em uma matriz de granulação média a fina, composta por quartzo, feldspato alcalino pertítico, biotita marrom e, em menor proporção, topázio e zircão. Já clorita, opacos, óxidos e/ou hidróxidos de ferro, mica branca e anatásio são fases acessórias de origem secundária. Os fenocristais de quartzo são subédricos,

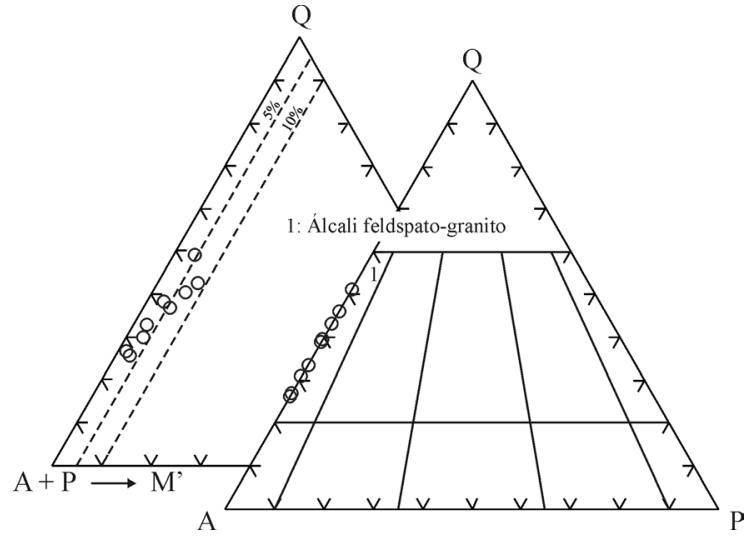

Figura 3 - Diagramas $Q-A-P$ e $Q-(A+P)-M$ ' (Streckeisen 1976) para as amostras do biotitaálcali feldspato granito com topázio, encaixante do greisen.

com limites irregulares e baías (Fig. 4c). Os fenocristais de feldspato alcalino mostram núcleos de plagioclásio primário intensamente alterado (textura antirapakivi). São euédricos a subédricos, fraturados e com embaiamentos, sugerindo reabsorção, localmente exibem pertitas em veios e manchas e desenvolvimento de albita intergranular (Fig. 4d). Na matriz, ocorrem intercrescimentos granofíricos entre quartzo e feldspato alcalino (Fig. 4e).

Leucogranito pegmatítico com cassiterita O leucogranito pegmatítico ocorre em contato com o biotita-álcali feldspato-granito com topázio e ambos são truncados por topázio-greisen. A forma do leucogranito pegmatítico não pôde ser visualizada, uma vez que somente uma pequena porção do mesmo (espessura $5-10 \mathrm{~cm}$ ) foi interceptada pelo furo de sondagem. É formado predominantemente por feldspato alcalino pertítico, quartzo e cassiterita. A albitização na rocha é expressiva, sendo marcada pela formação de albita em coroas trocadas nos contatos entre cristais de feldspato alcalino. A esfalerita preenche espaços intersticiais entre grãos de cassiterita e topázio, mostrando que a sua formação é claramente tardia em relação àqueles minerais (Fig. 4f).

\section{Biotita-álcali feldspato granito com topázio alterado} e cavidades de dissolução A greisenização do biotita-álcali feldspato-granito com topázio causa aumento gradativo nos conteúdos de topázio, mica e quartzo e diminuição do feldspato alcalino. Os granitos greisenizados apresentam, em geral, coloração rosa-avermelhada e textura hipidiomórfica média. A formação de cavidades de dissolução é outra característica marcante da greisenização.

Os principais efeitos da alteração hidrotermal são: (1) A albita tardia forma coroas trocadas entre cristais de feldspato potássico (Smith \& Brown 1988; Dall'Agnol et al. 1993); (2) feldspatos alcalinos pertíticos são transformados em albita chess-board; (3) cloritização da biotita; (4) formação de micas secundárias 
Tabela 1 - Composições modais das amostras representativas do biotita-álcali feldspato-granito com topázio do maciço Água Boa. Abreviações: Kfs - álcali feldspato, Sdf - siderofilita, Znw - zinnwaldita, Toz - topázio, Fl fluorita, Zr-zircão, Ant-anatásio, Chl-clorita, Op - opacos.

\begin{tabular}{|c|c|c|c|c|c|c|c|c|c|}
\hline \multirow{2}{*}{ Variedade } & \multicolumn{4}{|c|}{ Biotita-álcali feldspato-granito seriado } & \multicolumn{2}{|c|}{$\begin{array}{l}\text { Bt-Kfs-granito } \\
\text { porfirítico }\end{array}$} & \multirow{2}{*}{$\begin{array}{c}\begin{array}{c}\text { Granito } \\
\text { albitizado }\end{array} \\
\text { F06Gr/77,46 }\end{array}$} & \multicolumn{2}{|c|}{$\begin{array}{l}\text { Bt-Kfs-granito } \\
\text { greisenizado }\end{array}$} \\
\hline & $\mathrm{F} 06 \mathrm{Gr} / 12,15$ & $\mathrm{~F} 06 \mathrm{Gr} / 20,31$ & $\mathrm{~F} 06 \mathrm{Gr} / 49,28$ & $\mathrm{~F} 06 \mathrm{Gr} / 62,38$ & $\mathrm{~F} 06 \mathrm{Gr} / 84,64$ & $\mathrm{~F} 06 \mathrm{Gr} / 85,65$ & & $\mathrm{~F} 06 \mathrm{Gr} / 27,02$ & $\mathrm{~F} 06 \mathrm{Gr} / 86,82$ \\
\hline Quartzo & 40,0 & 35,8 & 32,0 & 26,3 & 25 & 35,8 & 28,2 & 38 & 47,4 \\
\hline $\begin{array}{l}\text { Feldspato } \\
\text { alcalino }\end{array}$ & 46,3 & 54,7 & 62,9 & 70,4 & 70,1 & 56,5 & $<0,1$ & 50 & 45 \\
\hline Albita & 0,7 & 3,2 & 0,0 & $<0,1$ & $<0,1$ & $<0,1$ & 63,2 & 1,5 & $<0,1$ \\
\hline Siderofilita & 8,4 & 3 & 2,2 & 1,2 & 2,2 & 4,5 & 2 & 7 & 4,4 \\
\hline Topázio & 1,1 & 1 & 0,4 & 0,2 & 0,4 & 0,7 & 1,3 & 0,4 & $<0,1$ \\
\hline Fluorita & 1,2 & 0,7 & 0,2 & 0,1 & 0,4 & 0,8 & 0,5 & 0,7 & 0,2 \\
\hline Zircão & 0,3 & 0,4 & 0,0 & $<0,1$ & $<0,1$ & 0,1 & 0,1 & 0,2 & $<0,1$ \\
\hline Opacos & 0,5 & 0,3 & 0,0 & 0,4 & 0,1 & 0,2 & 1,3 & $<0,1$ & 0,2 \\
\hline Anatásio & 0,1 & $<0,1$ & 0,4 & - & - & 0,1 & 0,3 & $<0,1$ & 0,1 \\
\hline Clorita & 0,1 & 0,1 & 0,1 & 0,2 & 0,8 & 0,8 & - & $<0,1$ & - \\
\hline Fengita & 1,3 & 0,8 & 1,7 & 1,2 & 1 & 0,5 & 3,1 & 2,2 & 2,5 \\
\hline Esfalerita & - & - & - & - & - & - & - & $<0,1$ & - \\
\hline Cassiterita & - & - & - & - & - & - & - & $<0,1$ & - \\
\hline$\sum \mathrm{M}^{\prime}$ & 9 & 3,8 & 2,7 & 1,8 & 3,1 & 5,7 & 3,7 & 7,2 & 4,7 \\
\hline$(\mathrm{Toz}+\mathrm{Fl})$ & 2,2 & 1,7 & 0,6 & 0,3 & 0,8 & 1,5 & 1,8 & 1,1 & 0,2 \\
\hline$\left(M^{\prime}+Z n w\right)$ & 10,3 & 4,6 & 4,5 & 3 & 4,1 & 6,2 & 6,8 & 9,4 & 7,2 \\
\hline \multicolumn{10}{|l|}{$100 \%$} \\
\hline Q & 46,3 & 39,6 & 33,7 & 27,2 & 26,3 & 38,8 & 30,9 & 43,2 & 51,3 \\
\hline $\mathrm{A}$ & 53,7 & 60,4 & 66,3 & 72,8 & 73,7 & 61,2 & 69,1 & 56,8 & 48,7 \\
\hline $\mathrm{P}$ & 0,0 & 0,0 & 0,0 & 0,0 & 0,0 & 0,0 & 0,0 & 0,0 & 0,0 \\
\hline
\end{tabular}

de cor verde pálido, bem como substituição parcial do topázio magmático por sericita (Fig. 4g); (5) formação de topázio secundário (Fig. 4h) e (6) venulação (albita). São identificadas ainda cavidades com diâmetro variável de 0,2 a $1 \mathrm{~cm}$, preenchidas por zircão, anatásio, cassiterita, fluorita, clorita, esfalerita e pirita (Fig. 4h).

Topázio-siderofilita-quartzo-greisen e quartzotopázio-siderofilita-greisen A tabela 2 mostra as composições modais, em percentagem, dos greisens estudados. O filossilicato mais abundante é a siderofilita, em geral, com conteúdo modal superior a $24 \%$; a zinnwaldita alcança proporção modal máxima de 5\% e está ausente em diversas amostras; a clorita ocorre localmente e apenas numa amostra apresenta conteúdo modal expressivo (Tab. 2). Além da siderofilita, quartzo e topázio formam a composição essencial dos greisens. Fluorita, cassiterita e esfalerita são os principais minerais acessórios, em termos de proporções modais. A cassiterita está presente em todas as amostras analisadas e seu conteúdo modal máximo atinge $2,7 \%$, ao passo que o de esfalerita é de $0,6 \%$. Zircão, opacos e monazita são minerais traços, com proporções modais inferiores a $0,5 \%$ e os dois últimos estão ausentes em muitas amostras. Restos de feldspato alcalino podem ainda ser encontrados nos greisens, sendo os seus conteúdos modais de até $12,8 \%$.

As composições modais das amostras de greisen (Tab. 2) foram plotadas no diagrama de Kuhne et al. (1972), distribuindo-se ao longo do campo IV e, subordinadamente, no campo VIII (Fig. 5), sendo classificadas como topázio-siderofilita-quartzo-greisen e quartzo-topázio-siderofilita-greisen, respectivamente. Uma única amostra plota no campo II, correspondente a topázio-quartzo-greisen (Fig. 5). Esses dados revelam a dominância de siderofilita sobre topázio, nos greisens da área Grota Rica. Quando plotadas em diagramas binários (Fig. 6a) constata-se que, excetuando-se o topázio-quartzo-greisen, as amostras incidem no campo dos greisens da zona da siderofilita, segundo classificação adotada para os greisens da área Guinho-Baixão (Borges 2002), refletindo a dominância da mica sobre o topázio na área estudada. É importante ressaltar, ainda, a correlação negativa entre topázio e feldspatos alca- 

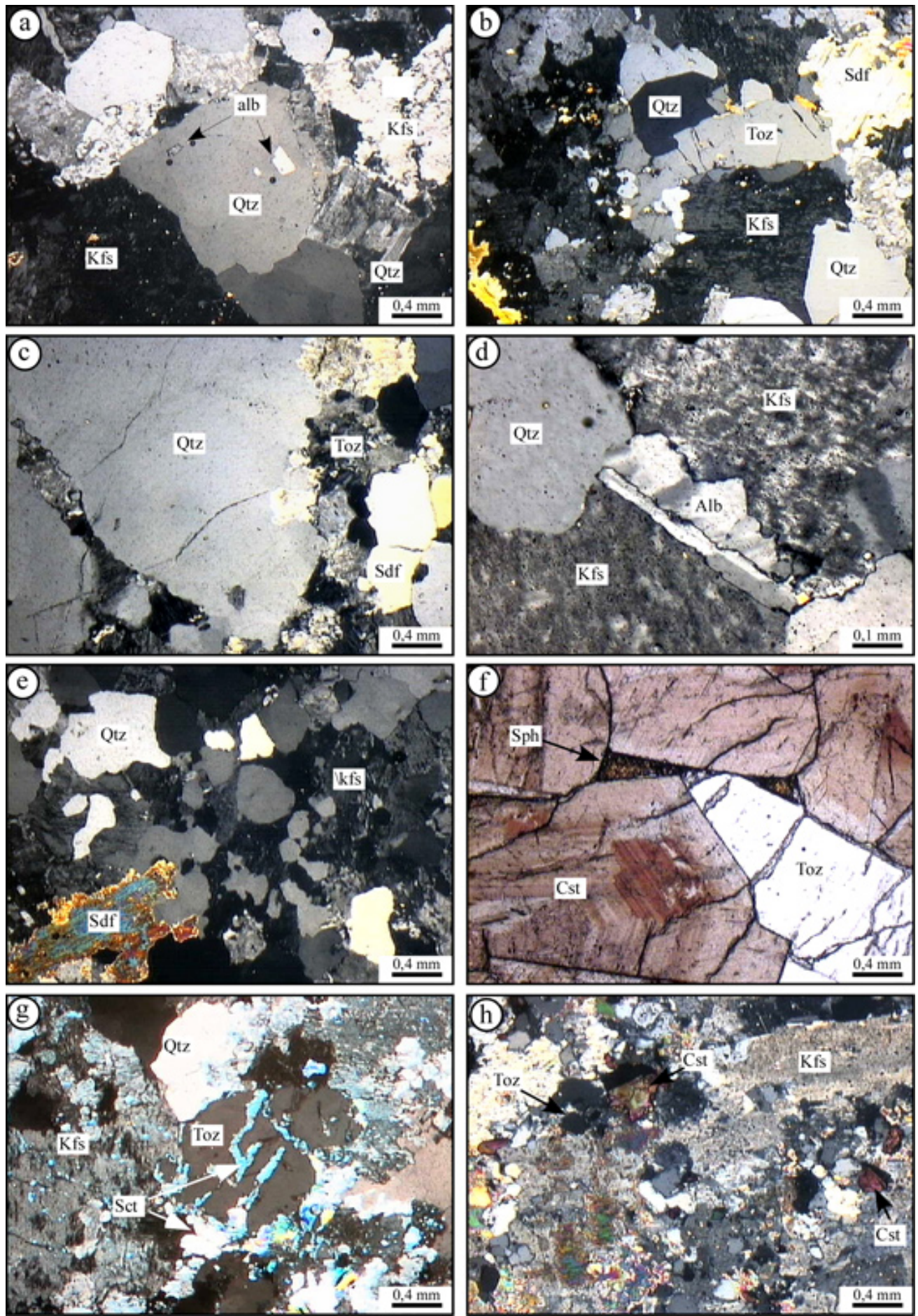

Figura 4 - Aspectos texturais do biotita-álcali feldspato-granito com topázio, leucogranito pegmatítico com cassiterita, biotita-álcali feldspato-granito com topázio alterado e cavidades de dissolução. (a) finos cristais de plagioclásio albítico inclusos em quartzo (seta)/NC; (b) cristal subédrico de topázio intersticial a cristais de quartzo e feldspato pertítico/NC; (c) fenocristais de quartzo, exibindo provável textura de reabsorção/NC; (d) albita intergranular, formando coroas trocadas entre cristais de feldspato alcalino/NC; (e) Intercrescimentos granofiricos entre feldspato alcalino e quartzo/NC; (f) ) esfalerita nos interstícios entre cristais subautomórficos de cassiterita e topázio; (g) sericita substituindo topázio magmático/NC; (h) sericitização de feldspato alcalino e preenchimento de cavidades por cassiterita e topázio tardios/NC. NC: nicóis cruzados. Simbologia: Sdf: siderofilita, Tpz: topázio, Qtz: quartzo, Ab: albita, Kfs: feldspato alcalino pertitico, Sph: esfalerita, Cst: cassiterita, Chl. 
Tabela 2 - Composições modais médias das diversas variedades de greisens associados a fácies biotita-álcalifeldspato-granito com topázio do maciço Água Boa. Abreviações: Sdf-siderofilita, Znw - zinnwaldita, Toz - topázio, Fl-fluorita.

\begin{tabular}{|c|c|c|c|c|c|c|c|c|}
\hline \multirow{2}{*}{$\begin{array}{l}\text { Variedade } \\
\text { Intervalo } \\
\text { Mineral }\end{array}$} & \multicolumn{5}{|c|}{ Topázio-siderofilita-quartzo-greisen } & \multicolumn{2}{|c|}{$\begin{array}{l}\text { Quartzo-topázio- } \\
\text { siderofilita-greisen }\end{array}$} & \multirow{2}{*}{$\begin{array}{c}\begin{array}{c}\text { Topázio-quartzo- } \\
\text { greisen }\end{array} \\
\text { F06Gr/49,28 }\end{array}$} \\
\hline & $\mathrm{F} 06 \mathrm{Gr} / 24,25$ & $\mathrm{~F} 06 \mathrm{Gr} / 43,83$ & $\mathrm{~F} 06 \mathrm{Gr} / 43,93$ & $\mathrm{~F} 06 \mathrm{Gr} / 56,04$ & $\mathrm{~F} 06 \mathrm{Gr} / 59,60$ & $\mathrm{~F} 06 \mathrm{Gr} / 40,40$ & $\mathrm{~F} 06 \mathrm{Gr} / 56,47$ & \\
\hline Quartzo & 51,1 & 47,7 & 50,6 & 50,6 & 54,7 & 44,5 & 41,3 & 59,6 \\
\hline Siderofilita & 17,3 & 34,6 & 30,3 & 24,8 & 31,2 & 29 & 30,9 & 0,7 \\
\hline Topázio & 12 & 12,6 & 10,4 & 16,8 & 8,4 & 19,3 & 23,5 & 34,6 \\
\hline Fluorita & 0,6 & 0,5 & 2,1 & 1 & 0,3 & $<0,1$ & 0,4 & 0,2 \\
\hline Zinnwaldita & 5 & - & 2,7 & - & - & 3,7 & 1 & 0,4 \\
\hline Esfalerita & 0,6 & 0,1 & 0,6 & 0,1 & 0,6 & $<0,1$ & 0,5 & - \\
\hline Opacos & 0,4 & - & 0,2 & - & $<0,1$ & 0,2 & $<0,1$ & - \\
\hline Cassiterita & 0,2 & 2,7 & $<0,1$ & $<0,1$ & $<0,1$ & 2,2 & $<0,1$ & 1 \\
\hline Zircão & $<0,1$ & 0,1 & $<0,1$ & $<0,1$ & 0,1 & 0,2 & $<0,1$ & $<0,1$ \\
\hline Anatásio & $<0,1$ & $<0,1$ & 0,2 & 0,1 & 0,2 & $<0,1$ & $<0,1$ & - \\
\hline Monazita & $<0,1$ & - & - & - & - & 0,6 & $<0,1$ & - \\
\hline Clorita & $<0,1$ & - & 2,9 & - & - & - & 0,8 & - \\
\hline Feldspato & 12,8 & 1,4 & $<0,1$ & 6,2 & 4,5 & 0,3 & 1,6 & 3,5 \\
\hline Sdf $+Z n w$ & 22,3 & 34,6 & 33 & 24,8 & 31,2 & 32,7 & 31,9 & 1,1 \\
\hline Toz $+\mathrm{Fl}$ & 12,6 & 13,1 & 12,5 & 17,8 & 8,7 & 19,3 & 23,9 & 34,8 \\
\hline \multicolumn{9}{|l|}{$100 \%$} \\
\hline Quartzo & 59,4 & 50,0 & 52,7 & 54,3 & 57,8 & 46,1 & 42,5 & 62,4 \\
\hline $\mathrm{Sdf}+\mathrm{Znw}$ & 25,9 & 36,3 & 34,3 & 26,6 & 33,0 & 33,9 & 32,9 & 1,2 \\
\hline Toz $+\mathrm{Fl}$ & 14,7 & 13,7 & 13,0 & 19,1 & 9,2 & 20,0 & 24,6 & 36,4 \\
\hline
\end{tabular}

linos, indicando que a diminuição dos feldspatos está intimamente relacionada ao aumento do topázio modal (Fig. 6b).

Os greisens apresentam textura granular média a fina, xenomórfica a hipidiomórfica, sendo que o quartzo desenvolve cristais anédricos $(0,4-1 \mathrm{~mm})$, por vezes fraturados, o topázio ocorre principalmente em massas ou agregados, na forma de prismas curtos, fraturados, com dimensão média em torno de 0,2 mm (Fig. 7a) e a fluorita inclusa na siderofilita ou em grãos intersticiais $(\sim 0,1 \mathrm{~mm})$.

A siderofilita constitui agregados de lamelas subédricas a euédricas, com dimensões entre 0,1 e 1,2 $\mathrm{mm}$, podendo chegar a $3 \mathrm{~mm}$ nas porções mais micáceas. Mostra pleocroísmo entre verde escuro e verde claro. Localmente, a clorita substitui a siderofilita. A zinnwaldita é claramente tardia, mostra pleocroísmo variando de amarelo-pálido a amarelo-esbranquiçado, e desenvolve-se, preferencialmente, nas bordas dos cristais de siderofilita.

A cassiterita ocorre disseminada e de duas maneiras: (a) agregados de pequenos cristais subédricos maclados e zonados $(\sim 0,3 \mathrm{~mm})$, entremeados a topázio e quartzo (Fig. 7b), ou (b) como grãos euédricos a subédricos de granulação fina a média (até $>1 \mathrm{~mm}$ ), associados com topázio, quartzo e siderofilita (Fig. 7c).

A esfalerita forma cristais subédricos a anédri- cos, com granulação fina e dimensões entre 0,3 e 1 mm e coloração amarelo-avermelhado. É mais abundante nos greisens mais ricos em siderofilita (Fig. 7d) e quando ocorre nos greisens mais ricos topázio preenche cavidades. A pirita ocorre como cristais euédricos a subédricos, seguidamente associada à esfalerita e/ou galena.

O anatásio mostra cor verde a levemente azulado, relevo muito alto e dimensão média $<0,1 \mathrm{~mm}$. Seus cristais associam-se a clorita, fluorita e cassiterita. O zircão, interpretado como de origem hidrotermal, forma cristais euédricos a subédricos $(\sim 0,2 \mathrm{~mm})$, fraturados, inclusos em siderofilita e quartzo. Monazita, óxidos de ETR e bismuto nativo completam a mineralogia.

Veios de quartzo Veios tabulares de espessura centimétrica $(5 \mathrm{~cm})$ de quartzo com granulação média a grossa cortam os greisens. Em geral, há duas variedades: (1) veios de quartzo com esfalerita; (2) veio de quartzo estéreis. Os primeiros são formados por quartzo e esfalerita, tendo como acessórios zinnwaldita, e raros cristais de topázio e galena. O quartzo forma cristais irregulares de granulação fina a média, com textura de crustificação e extinção ondulante (Fig. 7e), e cristais anédricos de granulação grossa e poligonalizados. A esfalerita forma grãos com coloração vermelho-escuro e granulação média a grossa (>1,2 mm). A zinnwaldita, 


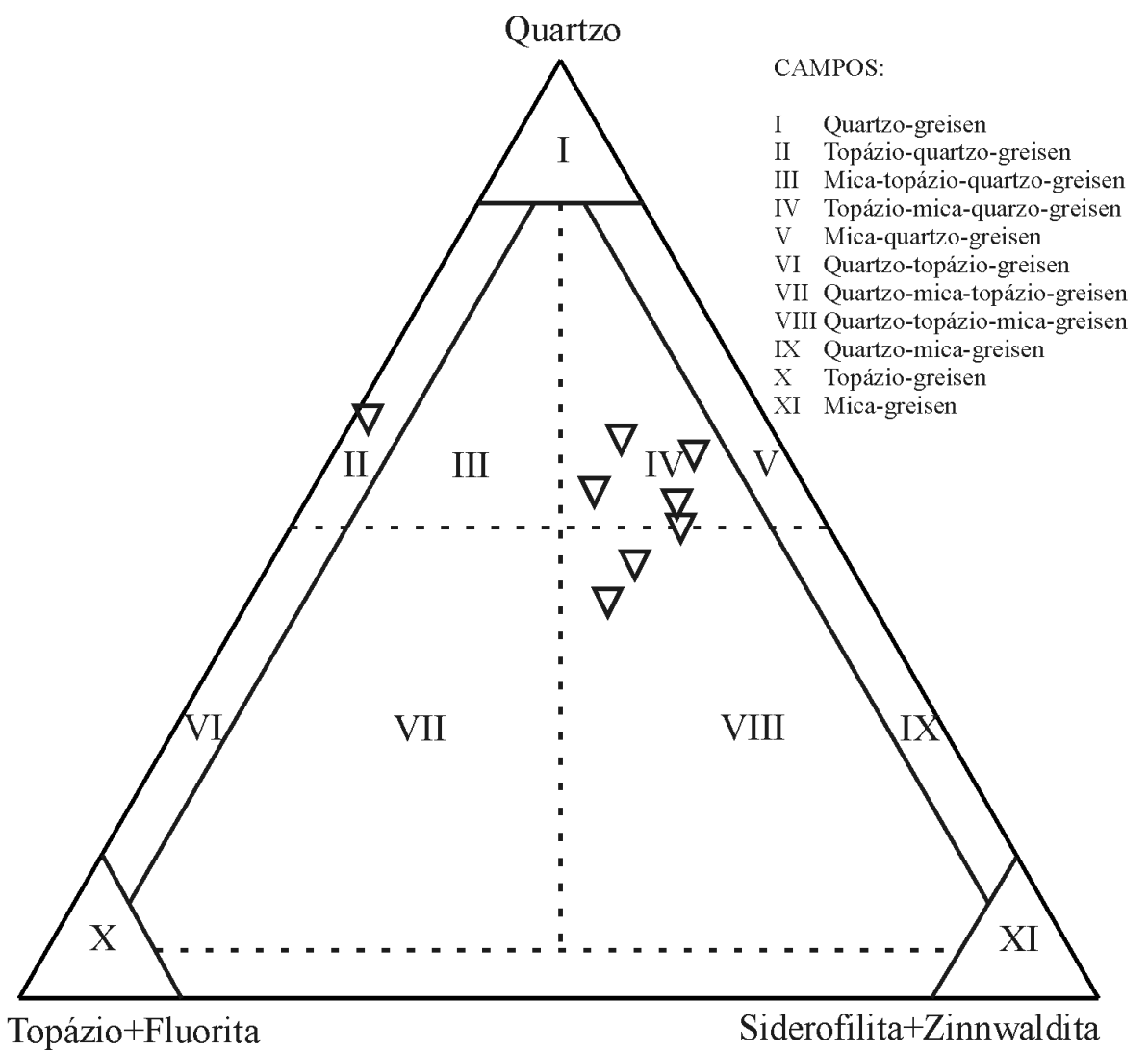

Figura 5 - Distribuição dos greisens associados à fácies biotita-álcali-feldspato-granito com topázio do maciço Água Boa no diagrama triangular de Kuhne et al. (1972).
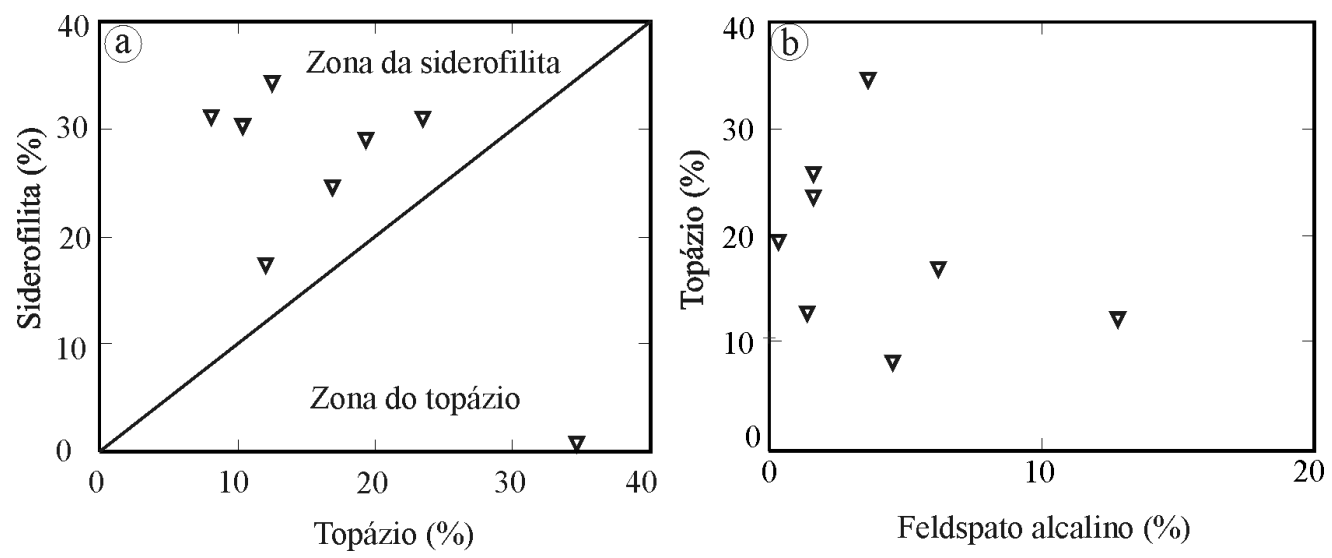

Figura 6 - Diagrama de correlação de minerais. (a) topázio x siderofilita (b) feldspato alcalino x topázio. Campos das zonas de siderofilita e topázio segundo Borges (2002).

mica com pleocroísmo de verde claro a branco, ocorre localmente na borda da esfalerita (Fig. 7f).

SUCESSÃO PARAGENÉTICA Uma síntese da sucessão paragenética estabelecida para as rochas da zona hidrotermalizada é apresentada na figura 8. Os diversos estágios de formação das rochas estudadas e a sucessão na ordem de cristalização dos diferentes minerais que as constituem foram definidas com base em observações petrográficas mesoscópicas e microscópicas. Além das relações texturais descritas anteriormente, são assinaladas abaixo algumas observações adicionais que contribuíram na definição das seqüências paragenéticas.

Estágio Magmático Zircão e ferro-columbita precedem na seqüência de cristalização do granito as fases 

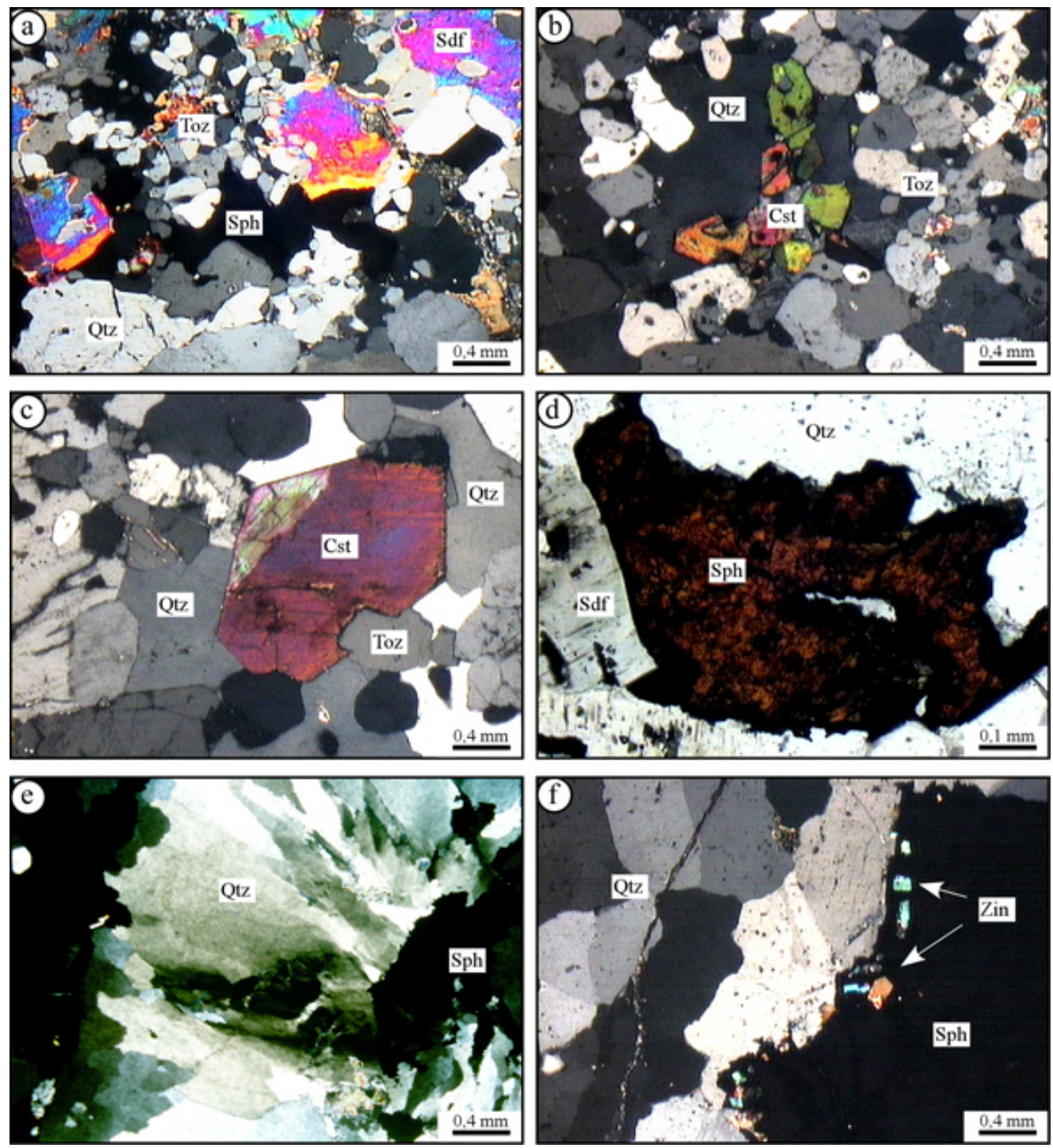

Figura 7 - Aspectos mineralógicos e texturais do topázio-quartzo-siderofilita-greisen e topázio-siderofilita-quartzo-greisen. (a) textura granular, exibindo topázio, quartzo, siderofilita em agregados, com preenchimento de esfalerita tardia/NC; (b) cristais subédricos de cassiterita junto a agregados de topázio e quartzo/NC; (c) cassiterita euédrica, zonada e maclada, mostrando contatos retilíneos com quartzo e irregulares com topázio; (d) cristal anédrico de esfalerita avermelhada com contato muito irregular com quartzo e reto com siderofilita verde/NC; (e) quartzo tardio com textura de crustificação e extinção ondulante em contato com esfalerita/NC; (f) zinnwaldita associada à esfalerita/NC. NC: Nicóis cruzados. Simbologia: Toz: topázio, Qtz: quartzo, Sdf: siderofilita, Sph: esfalerita, Cst: cassiterita, Znw: zinnwaldita.

essenciais representadas por fenocristais de quartzo, feldspato alcalino, e siderofilita marrom, uma vez que os primeiros ocorrem exclusivamente como inclusões nas últimas. A textura porfirítica, bem como os intercrescimentos granofíricos ao redor dos fenocristais de quartzo e feldspato, indicam que houve, no mínimo, dois estágios distintos de cristalização permitindo, primeiramente, a formação lenta de grandes cristais, seguida de cristalização relativamente rápida com formação de matriz mais fina, localmente granofírica. Raras inclusões de albita magmática nas bordas de fenocristais de quartzo sugerem que ela deve ter iniciado a cristalização próxima ao final do estágio magmático.
Estágio Magmático (supercrítico) Após a formação do topázio-granito, um líquido supercrítico provocou a formação localizada de leucogranitos pegmatíticos com cassiterita.

Estágio Pós-magmático Primeiramente, granito e leucogranito pegmatítico interagiram com soluções ricas em sódio, que induziram a formação de albita chessboard e intergranular entre cristais de feldspato alcalino. Vênulas de albita também cortam essas rochas.

A greisenização, estágio de alteração hidrotermal mais intenso, imprimiu ao granito mudanças radicais em mineralogia e textura, devidas principalmente 


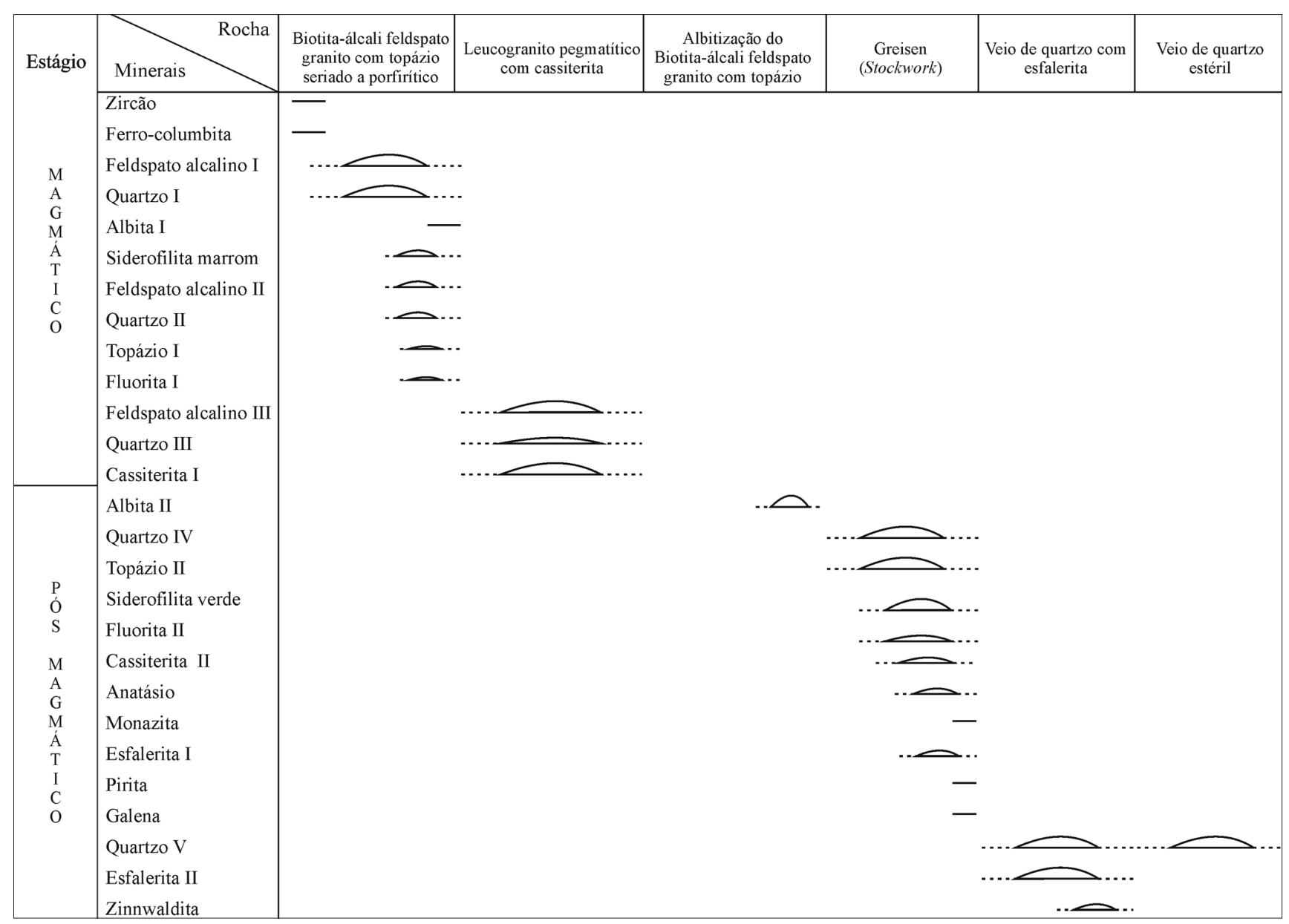

Figura 8 - Quadro paragenético das rochas da fácies topázio-granito, greisens e veios de quartzo relacionados ao maciço Água Boa.

à desestabilização e praticamente total dissolução ou substituição dos feldspatos alcalinos. A silicificação, posterior à greisenização, foi responsável pela formação de veios de quartzo leitosos estéreis ou com esfalerita \pm zinnwaldita.

GEOQUÍMICA As análises químicas em rocha total (Tab. 3) foram realizadas no Acme Analytical Laboratories Ltda. (Vancouver, Canadá), onde foram dosados os conteúdos de elementos maiores e menores $\left(\mathrm{SiO}_{2}\right.$, $\mathrm{Al}_{2} \mathrm{O}_{3}, \mathrm{Fe}_{2} \mathrm{O}_{3} \mathrm{t}, \mathrm{MgO}, \mathrm{CaO}, \mathrm{Na}_{2} \mathrm{O}, \mathrm{TiO}_{2}, \mathrm{Cr}_{2} \mathrm{O}_{3}, \mathrm{P}_{2} \mathrm{O}_{5}$, $\mathrm{PF}$ ), traço (Zn, Cu, Pb, Ba, Be, Cs, Ga, Hf, Nb, Rb, Sn, $\mathrm{Sr}, \mathrm{Ta}, \mathrm{Th}, \mathrm{U}, \mathrm{W}, \mathrm{Zr}, \mathrm{Y}, \mathrm{Bi})$ e terras raras (La, Ce, Pr, $\mathrm{Nd}, \mathrm{Sm}, \mathrm{Eu}, \mathrm{Gd}, \mathrm{Tb}, \mathrm{Dy}, \mathrm{Ho}, \mathrm{Er}, \mathrm{Tm}, \mathrm{Yb}$ e Lu). Os elementos maiores foram analisados por ICP-ES e os elementos traço e terras raras por ICP-MS. O F foi dosado por análise de eletrodo de íon específico, após fusão em $\mathrm{NaOH}$. As dosagens de $\mathrm{FeO}$ em amostras de granitos foram realizadas por titulação no Laboratório de Análises Químicas do Centro de Geociências da UFPA. O conteúdo de $\mathrm{Fe}_{2} \mathrm{O}_{3}$ foi obtido pela equação $\mathrm{Fe}_{2} \mathrm{O}_{3}=\mathrm{FeO}$ * 1,1113 subtraído do $\mathrm{Fe}_{2} \mathrm{O}_{3}$ t. Para os greisens foram utilizados apenas os teores de $\mathrm{Fe}_{2} \mathrm{O}_{3} \mathrm{t}$, haja vista que os cálculos para obtenção do $\mathrm{Fe}_{2} \mathrm{O}_{3}$ revelaram valores negativos, provavelmente devido à̀ grande quantidade de sulfetos nessas rochas.
O topázio-granito, encaixante dos greisens estudados, mostra caráter peraluminoso e teores elevados de $\mathrm{SiO}_{2}, \mathrm{~K}_{2} \mathrm{O}, \mathrm{Rb}, \mathrm{Nb}, \mathrm{Ga}, \mathrm{Y}, \mathrm{Th}, \mathrm{U}$, Sn e F, moderados de $\mathrm{Al}_{2} \mathrm{O}_{3}, \mathrm{Na}_{2} \mathrm{O}, \mathrm{Zr}$ e $\mathrm{Pb}$ e muito baixos de $\mathrm{MgO}, \mathrm{CaO}$, $\mathrm{Fe}_{2} \mathrm{O}_{3} \mathrm{t}, \mathrm{MnO}, \mathrm{TiO}_{2}, \mathrm{P}_{2} \mathrm{O}_{5}, \mathrm{Ba}, \mathrm{Sr}, \mathrm{S}, \mathrm{Zn}$ e $\mathrm{Cu}$. A composição química em termos dos elementos maiores, menores e traços para as rochas de Pitinga são consistentes com aqueles observados para granitos estaníferos (Tischendorf 1977). O topázio-granito do pluton Água Boa apresenta características geoquímicas similares as dos granitos classificados na literatura internacional como anorogênicos, intraplacas, ou tipo-A, segundo a classificação sugerida por Loiselle \& Wones (1979) e os critérios geoquímicos definidos por Collins et al. (1982) e Whalen et al. (1987). Isto é coerente com as características geoquímicas das diferentes variedades de granito da Suíte Madeira (Lenharo 1998, Costi et al. 2000, 2005, Costi 2000, Lenharo et al. 2002). São rochas com alta sílica $(75,85$ - 77,12\%), somatório de álcalis entre 7,9 e $8,5 \%$, razões $\mathrm{K}_{2} \mathrm{O} / \mathrm{Na}_{2} \mathrm{O}$ sempre superiores a unidade e razões $\mathrm{Fe}_{2} \mathrm{O}_{3} \mathrm{t} /\left(\mathrm{Fe}_{2} \mathrm{O}_{3} \mathrm{t}+\mathrm{MgO}\right)$ extremamente elevadas, em torno de 0,98 (Tab. 3).

O comportamento geoquímico do granito albitizado quando comparado ao topázio-granito mostra que há enriquecimento no primeiro em $\mathrm{Al}_{2} \mathrm{O}_{3}, \mathrm{Fe}_{2} \mathrm{O}_{3} \mathrm{t}, \mathrm{CaO}$, $\mathrm{Na}_{2} \mathrm{O}$, e empobrecimento em $\mathrm{TiO}_{2}$ e $\mathrm{K}_{2} \mathrm{O}$, enquanto o $\mathrm{F}$ 

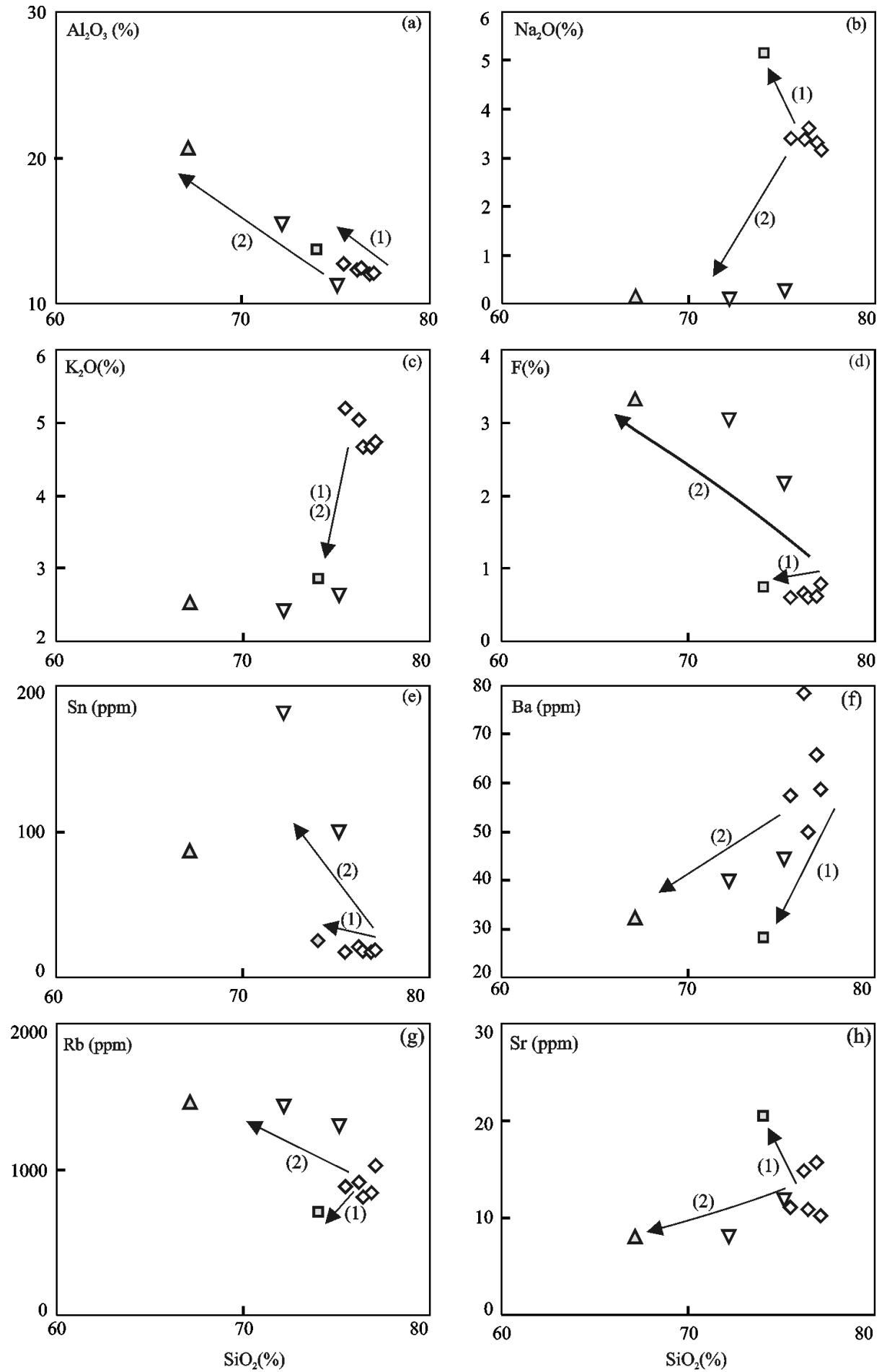

$\diamond$ Biotita-álcali feldspato-granito com topázio

$\nabla$ Quartzo-topázio-siderofilita-greisen

口 Biotita-álcali feldspato-granito com topázio albitizado

$\Delta$ Topázio-siderofilita-quartzo-greisen

Figura 9 - Diagramas de variação das amostras do biotita-álcali feldspatogranito com topázio, granito albitizado e greisens. A seta (1) indica o trend de evolução no sentido granito-granito albitizado e a seta (2) representa o trend de evolução no sentido granito-greisen.

não mostrou variação expressiva (Tab. 3; Fig. 9, Trend 1). Dentre os elementos-traço, Sn, Sr e Y apresentaram um leve enriquecimento ao longo da transformação, enquanto que $\mathrm{Cl}, \mathrm{Ba}, \mathrm{Rb}, \mathrm{Pb}, \mathrm{Th}, \mathrm{Zr}$ e $\mathrm{Nb}$ decresceram.

Os greisens mostram-se, em relação ao protóli- to granítico, relativamente enriquecidos em $\mathrm{Al}_{2} \mathrm{O}_{3}, \mathrm{Fe}_{2}$ $\mathrm{O}_{3} \mathrm{t}, \mathrm{MnO}, \mathrm{F}, \mathrm{P} . \mathrm{F} ., \mathrm{S}, \mathrm{Zn}, \mathrm{Pb}$, Sn e Rb e empobrecidos em $\mathrm{Na}_{2} \mathrm{O}, \mathrm{K}_{2} \mathrm{O}, \mathrm{Cl}$, Th, Ba, Sr, Y e Nb (Fig. 9, Tab. 3). Os conteúdos de $\mathrm{TiO}_{2}, \mathrm{CaO}$ e $\mathrm{Zr}$ são similares nos dois tipos de rocha. Como particularidade, registra-se 

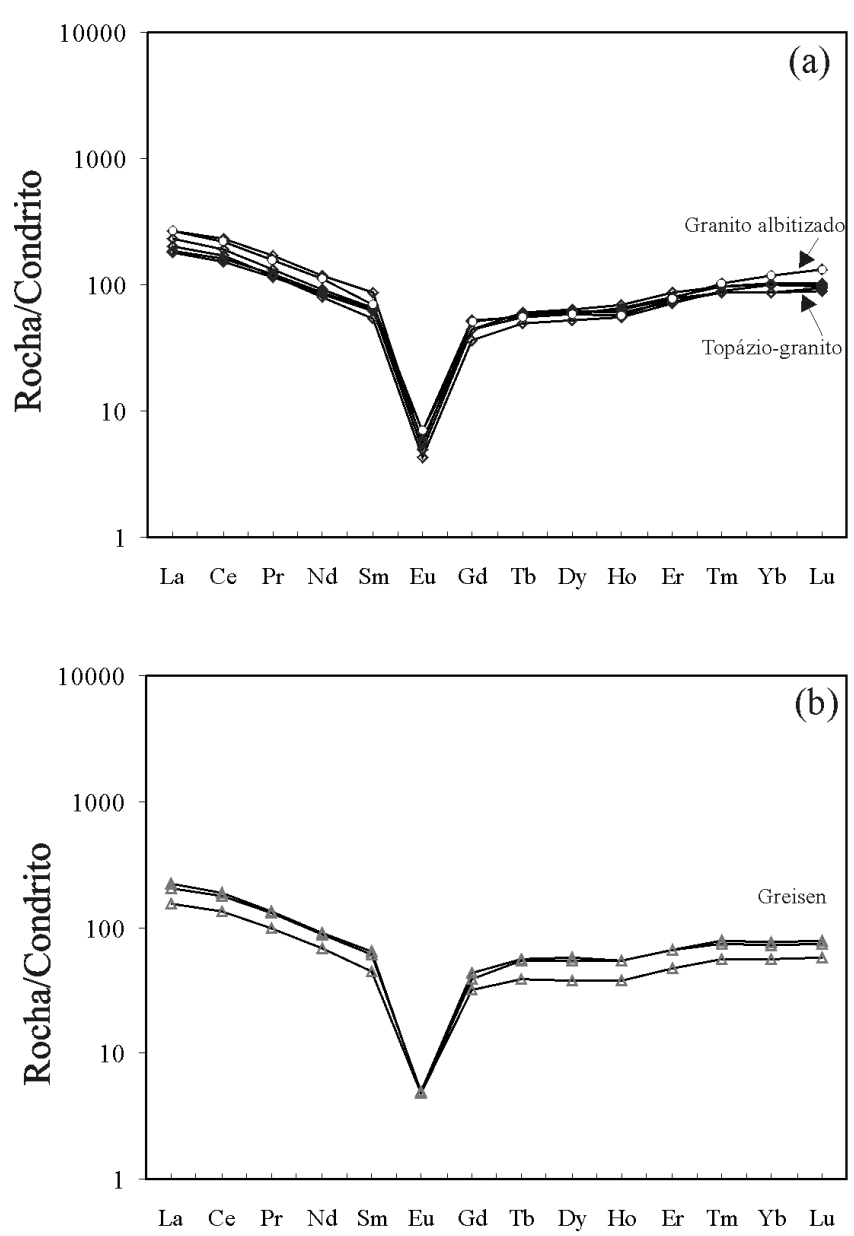

Figura 10 - Padrões de ETR. a) biotita-álcali feldspato-granito com topázi o e granito albitizado; b) greisen. Valores normalizados segundo os valores condríticos de Evensen et al. (1979).

o decréscimo relativo de $\mathrm{Al}_{2} \mathrm{O}_{3}$ em relação ao granito em uma das amostras de topázio-siderofilita-quartzogreisen (Fig. 9a, Tab. 3).

No que se refere às concentrações de elementos terras raras (ETR), os padrões das amostras analisadas normalizados ao condrito C1 (Evensen et al. 1978), revelam que as rochas da fácies topázio-granito são apenas ligeiramente enriquecidas em ETR leves em relação aos ETR pesados (Fig. 10). Em relação ao Eu, estas rochas apresentam anomalia negativa extremamente acentuada $\left(\mathrm{Eu} / \mathrm{Eu}^{*}=0,08-0,13\right)$, o que, juntamente com o fracionamento pouco expressivo de ETR pesados (razão média $\left.[\mathrm{La} / \mathrm{Yb}]_{\mathrm{N}}=2,2\right)$, determinando padrões em 'gaivota', são feiçõ̃es geoquímicas características de granitos evoluídos e típicas de fusões graníticas portadoras de F e Sn (Taylor \& Fryer 1983, Haapala 1997). Os padrões de ETR das amostras dos greisens são similares aos do topázio-granito (Fig. 10).

\section{BALANÇO DE MASSAS}

Introdução Técnicas de balanço de massa são aplicadas no estudo de sistemas hidrotermais com o intuito de quantificar as perdas e ganhos dos componentes químicos presentes nas rochas das zonas de alteração. $\mathrm{O}$ es- tudo da mobilidade relativa dos componentes químicos durante os processos metassomáticos responsáveis pela formação das rochas hidrotermalizadas da área Grota Rica foi efetuado com base em cálculos de perdas e ganhos (Balanço geoquímico de massa), conforme o método isocônico de Grant (1986). As medidas de densidade das rochas foram feitas no Laboratório de Mineralogia, associado ao Museu de Mineralogia do Centro de Geociências (UFPA). Tais métodos foram discutidos e aplicados anteriormente no estudo dos greisens da área Guinho-Baixão do corpo Água Boa (Borges 2002), sendo o referido estudo referência para o presente trabalho, até mesmo pela semelhança petrográfica e geoquímica entre os greisens com topázio e siderofilita das duas áreas de ocorrência do corpo Água Boa.

O método das isóconas, proposto por Grant (1986), se baseia na equação básica de Gresens (1967) e estabelece uma relação linear entre a concentração de um componente na rocha alterada e sua concentração na rocha original. Neste estudo, os cálculos de perdas de ganhos foram efetuados por meio das equações:

$$
\begin{gathered}
\mathrm{C}_{\mathrm{i}}^{\mathrm{A}}=\mathrm{M}^{\mathrm{O}} / \mathrm{M}^{\mathrm{A}}\left(\mathrm{C}_{\mathrm{i}}^{\left.\mathrm{O}+\Delta \mathrm{C}_{\mathrm{i}}\right)}\right. \\
\text { (Equação Básica) }
\end{gathered}
$$

$$
\Delta \mathrm{M}_{\mathrm{i}}=\left[\left(\mathrm{M}^{\mathrm{A}} / \mathrm{M}^{\mathrm{O}}\right) \mathrm{C}_{\mathrm{I}}^{\mathrm{A}}-\mathrm{C}_{\mathrm{I}}^{\mathrm{O}}\right] \mathrm{M}^{\mathrm{O}}
$$

onde:

$\mathrm{M}^{\mathrm{O}}$ e $\mathrm{M}^{\mathrm{A}}$ : Massas contidas em um mesmo volume de rocha, no protólito e em seu equivalente alterado, respectivamente;

$\Delta \mathrm{M}_{\mathrm{i}}$ : Ganho ou perda de massas de um componente i relativo à sua massa de referência;

$\mathrm{C}_{\mathrm{I}}^{\mathrm{O}}, \mathrm{C}_{\mathrm{I}}^{\mathrm{A}}$ : Concentração de um componente i antes e após a alteração;

$\Delta \mathrm{C}_{\mathrm{i}}$ : Diferença entre as massas inicial e final do componente i no sistema.

O método das isóconas é um método gráfico onde para cada componente é aplicada uma equação similar à expressão básica, na qual $\left(\mathrm{M}^{\mathrm{O}} / \mathrm{M}^{\mathrm{A}}\right)$ é constante. Os dados analíticos de $\mathrm{C}_{\mathrm{I}}^{\mathrm{A}}$ versus $\mathrm{C}_{\mathrm{I}}^{\mathrm{O}}$ são lançados em um diagrama binário. Existem vários parâmetros que podem servir de base para a definição da isócona, sendo a escolha entre eles subjetiva: (a) assumir que certos elementos se comportaram como imóveis durante a alteração; (b) assumir massa constante durante a alteração; (c) assumir volume constante durante a alteração; ou (d) definir uma reta com base em dados químicos coerentes que se disponham linearmente (best fit). Componentes que se encontram acima ou abaixo da isócona de referência foram, respectivamente, adicionados ou removidos durante a alteração.

A técnica de balanço de massa (Massa-Volume) de Gresens (1967) compara o fator de volume $\left(\mathrm{F}_{\mathrm{v}}\right)$ para cada elemento analisado para avaliar se o mesmo pode ser usado como um fator de correlação. $\mathrm{O}$ raciocínio adotado é que a coincidência dos valores de $\mathrm{F}_{\mathrm{v}}$ indicaria um comportamento coerente do elemento e, portanto, sua imobilidade. Contudo, isso nem sempre funciona 
Tabela 3 - Composição química do biotita-álcali-feldspato-granito com topázio, granito albitizado e greisen.

\begin{tabular}{|c|c|c|c|c|c|c|c|c|c|}
\hline \multirow{3}{*}{$\begin{array}{l}\text { Rocha } \\
\text { Intervalo }\end{array}$} & \multirow{2}{*}{\multicolumn{5}{|c|}{ Biotita-álcali feldspato-granito seriado a porfirítico }} & \multirow{3}{*}{$\begin{array}{c}\text { Granito } \\
\text { Albitizado } \\
77.46- \\
77.51\end{array}$} & \multicolumn{3}{|c|}{ Greisen } \\
\hline & & & & & & & \multirow{2}{*}{\begin{tabular}{|c|} 
Toz-sdf-qtz \\
$56,04-$ \\
56,09
\end{tabular}} & \multirow{2}{*}{\begin{tabular}{c|} 
Qtz-toz-sdf \\
$56,47-$ \\
56,52
\end{tabular}} & \multirow{2}{*}{\begin{tabular}{|c|} 
Toz-sdf-qtz \\
$59,60-$ \\
59,65 \\
\end{tabular}} \\
\hline & $\begin{array}{c}12.15- \\
12.20\end{array}$ & $\begin{array}{c}20.31- \\
20.36\end{array}$ & $\begin{array}{c}22.77- \\
23.40\end{array}$ & $\begin{array}{r}49.28 \\
49.33\end{array}$ & $\begin{array}{c}89.43- \\
89.48\end{array}$ & & & & \\
\hline$d\left(\mathrm{~g} / \mathrm{cm}^{3}\right)$ & 2,62 & 2,64 & 2,63 & 2,63 & 2,62 & 2,61 & 3,02 & 2,95 & 2,85 \\
\hline $\mathrm{SiO}_{2}$ & 76,18 & 75,85 & 76,43 & 76,87 & 77,12 & 74,05 & 72,16 & 67,12 & 75,12 \\
\hline $\mathrm{TiO}_{2}$ & 0,10 & 0,09 & 0,08 & 0,11 & 0,08 & 0,06 & 0,10 & 0,08 & 0,09 \\
\hline $\mathrm{Al}_{2} \mathrm{O}_{3}$ & 12,27 & 12,71 & 12,42 & 12,02 & 12,07 & 13,73 & 15,47 & 20,67 & 11,21 \\
\hline $\mathrm{FeO}$ & 0,93 & 0,70 & 0,59 & 1,15 & 0,92 & 0,45 & 4,89 & 4,51 & n.a. \\
\hline $\mathrm{Fe}_{2} \mathrm{O}_{3}$ & 0,33 & 0,50 & 0,64 & 0,23 & 0,44 & 1,36 & 0,05 & 0,57 & n.a. \\
\hline $\mathrm{Fe}_{2} \mathrm{O}_{3} \mathrm{t}$ & 1,36 & 1,28 & 1,30 & 1,51 & 1,46 & 1,86 & 5,48 & 5,58 & 4,98 \\
\hline $\mathrm{MgO}$ & 0,03 & 0,02 & 0,03 & 0,05 & 0,02 & 0,03 & 0,02 & 0,02 & 0,04 \\
\hline $\mathrm{MnO}$ & 0,03 & 0,03 & 0,03 & 0,04 & 0,02 & 0,03 & 0,24 & 0,22 & 0,18 \\
\hline $\mathrm{CaO}$ & 0,61 & 0,63 & 0,61 & 0,69 & 0,63 & 1,03 & 0,72 & 0,78 & 0,81 \\
\hline $\mathrm{Na}_{2} \mathrm{O}$ & 3,37 & 3,39 & 3,61 & 3,31 & 3,17 & 5,17 & 0,09 & 0,09 & 0,26 \\
\hline $\mathrm{K}_{2} \mathrm{O}$ & 5,04 & 5,19 & 4,66 & 4,67 & 4,74 & 2,86 & 2,42 & 2,53 & 2,64 \\
\hline $\mathrm{P}_{2} \mathrm{O}_{5}$ & 0,01 & 0,01 & 0,01 & 0,01 & 0,02 & 0,01 & 0,01 & 0,02 & 0,02 \\
\hline $\mathrm{Zn}$ & 0,02 & 0,02 & 0,01 & 0,01 & 0,01 & 0,01 & 1,16 & 0,71 & 2,08 \\
\hline $\mathrm{F}$ & 0,66 & 0,61 & 0,61 & 0,62 & 0,79 & 0,75 & 3,04 & 3,32 & 2,17 \\
\hline $\mathrm{S}$ & 0,01 & 0,01 & 0,11 & 0,15 & 0,01 & 0,01 & 0,65 & 0,35 & 1,17 \\
\hline $\mathrm{CO}_{2}$ & 0,11 & 0,11 & 0,11 & 0,33 & 0,07 & 0,18 & 0,14 & 0,14 & 0,07 \\
\hline $\mathrm{PF}$ & 1,20 & 1,00 & 1,00 & 0,90 & 0,90 & 1,30 & 1,80 & 2,00 & 2,00 \\
\hline Total & 100,89 & 100,87 & 100,96 & 101,17 & 101,00 & 101,03 & 102,96 & 103,13 & 102,84 \\
\hline $\mathrm{O} \Xi \mathrm{F}$ & 0,28 & 0,26 & 0,26 & 0,26 & 0,33 & 0,32 & 1,28 & 1,40 & 0,91 \\
\hline TOTAL & 100,62 & 100,61 & 100,70 & 100,91 & 100,67 & 100,72 & 101,68 & 101,73 & 101,93 \\
\hline $\mathrm{Fe}_{2} \mathrm{O}_{3} \mathrm{t} /\left(\mathrm{Fe}_{2} \mathrm{O}_{3} \mathrm{t}+\mathrm{MgO}\right)$ & 0,98 & 0,98 & 0,98 & 0,97 & 0,99 & 0,98 & 1,00 & 1,00 & 0,99 \\
\hline \multicolumn{10}{|l|}{ Elementos-traço (ppm) } \\
\hline $\mathrm{Cl}$ & 37 & 32 & 31 & 41 & 9 & 35 & 15 & 17 & 16 \\
\hline $\mathrm{Cu}$ & 2,7 & 1,8 & 2,3 & 1,7 & 2,5 & 3,2 & 19 & 23 & 45,7 \\
\hline $\mathrm{Pb}$ & 45,5 & 24,4 & 39,4 & 22,3 & 28,7 & 10,1 & 181,7 & 244,1 & 251,7 \\
\hline $\mathrm{Ba}$ & 78,4 & 57,4 & 49,8 & 65,7 & 58,7 & 28,3 & 39,8 & 32,2 & 44,4 \\
\hline $\mathrm{Be}$ & 9 & 7 & 10 & 8 & 111 & 19 & 5 & 5 & 14 \\
\hline $\mathrm{Ga}$ & 29,4 & 29,5 & 29,5 & 28 & 30,8 & 35,1 & 41 & 39,3 & 32,9 \\
\hline $\mathrm{Hf}$ & 9,9 & 14,4 & 11,1 & 14,8 & 7,2 & 5,3 & 10,5 & 9,7 & 11,2 \\
\hline $\mathrm{Nb}$ & 55 & 63,7 & 65,5 & 52 & 60,5 & 51,7 & 39 & 39,6 & 43,6 \\
\hline $\mathrm{Rb}$ & 911,5 & 882,9 & 811,7 & 837,9 & 1023,9 & 709,7 & 1434,4 & 1461,4 & 1300,6 \\
\hline $\mathrm{Sn}$ & 21 & 17 & 18 & 17 & 19 & 25 & 181 & 87 & 100 \\
\hline $\mathrm{Sr}$ & 14,8 & 11,1 & 10,9 & 15,7 & 10,2 & 20,5 & 8,1 & 8,1 & 11,8 \\
\hline $\mathrm{Ta}$ & 5,9 & 6,7 & 6,7 & 6,8 & 14,2 & 11,3 & 6,6 & 9,1 & 9,6 \\
\hline Th & 62,9 & 71,6 & 70,3 & 75,5 & 51,1 & 38,7 & 57,1 & 54,2 & 59,6 \\
\hline $\mathrm{U}$ & 32,4 & 23,2 & 21,4 & 19,8 & 30,2 & 16,3 & 29,8 & 20,1 & 32,1 \\
\hline $\mathrm{W}$ & 32,9 & 33,3 & 55,1 & 50 & 37,1 & 106,6 & 53,2 & 86,4 & 39,4 \\
\hline $\mathrm{Zr}$ & 185,1 & 218,8 & 181,4 & 258 & 134,9 & 59,9 & 177,8 & 168 & 197,3 \\
\hline $\mathrm{Y}$ & 124,1 & 148,3 & 136,2 & 121,2 & 108,2 & 146,7 & 105 & 80,9 & 108,5 \\
\hline \multicolumn{10}{|l|}{ Terras Raras (ppm) } \\
\hline $\mathrm{La}$ & 56,6 & 45,2 & 43,9 & 65,2 & 49,4 & 65,1 & 54,4 & 37,7 & 50,1 \\
\hline $\mathrm{Ce}$ & 120,4 & 102,2 & 97,1 & 140,9 & 108,9 & 149,8 & 120,9 & 86,7 & 114,6 \\
\hline $\operatorname{Pr}$ & 12,8 & 11,82 & 11,22 & 15,29 & 11,53 & 16,32 & 12,81 & 9,41 & 12,62 \\
\hline $\mathrm{Nd}$ & 43,3 & 41,7 & 39,9 & 53,7 & 37,5 & 55,4 & 43,1 & 32,5 & 41,2 \\
\hline $\mathrm{Sm}$ & 10 & 9,7 & 9,6 & 10,6 & 8,4 & 13,4 & 10 & 6,9 & 9,5 \\
\hline $\mathrm{Eu}$ & 0,4 & 0,29 & 0,34 & 0,4 & 0,25 & 0,32 & 0,28 & 0,28 & 0,29 \\
\hline $\mathrm{Gd}$ & 9,02 & 9,13 & 9,07 & 10,58 & 7,45 & 10,56 & 7,91 & 6,56 & 8,94 \\
\hline $\mathrm{Tb}$ & 2,29 & 2,27 & 2,07 & 2,1 & 1,85 & 2,14 & 2,05 & 1,45 & 2,08 \\
\hline Dy & 15,17 & 16,41 & 14,88 & 15,63 & 13,26 & 14,73 & 13,93 & 9,69 & 14,83 \\
\hline Ho & 3,64 & 3,89 & 3,74 & 3,42 & 3,18 & 3,24 & 3,11 & 2,15 & 3,12 \\
\hline $\mathrm{Er}$ & 13 & 14,25 & 13,2 & 12,04 & 12 & 12,73 & 11,02 & 7,91 & 11,13 \\
\hline $\mathrm{Tm}$ & 2,23 & 2,48 & 2,51 & 2,25 & 2,28 & 2,64 & 1,89 & 1,44 & 2,02 \\
\hline $\mathrm{Yb}$ & 14,44 & 16,86 & 16,43 & 14,53 & 16,35 & 19,68 & 12 & 9,3 & 12,59 \\
\hline $\mathrm{Lu}$ & 2,37 & 2,62 & 2,46 & 2,25 & 2,57 & 3,39 & 1,9 & 1,47 & 1,99 \\
\hline$\Sigma$ ETR & 305,66 & 278,82 & 266,42 & 348,89 & 274,92 & 369,45 & 295,3 & 213,46 & 285,01 \\
\hline$(\mathrm{La} / \mathrm{Yb})_{\mathrm{N}}$ & 2,65 & 1,81 & 1,80 & 3,03 & 2,04 & 2,23 & 3,06 & 2,74 & 2,69 \\
\hline$(\mathrm{La} / \mathrm{Lu})_{\mathrm{N}}$ & 2,48 & 1,79 & 1,85 & 3,01 & 2,00 & 1,99 & 2,97 & 2,66 & 2,61 \\
\hline
\end{tabular}


em sistemas hidrotermais que contém flúor, porque muitos elementos tradicionalmente considerados como imóveis mostram mobilidade nestes sistemas.

O método empregado depende, portanto, basicamente da definição de elementos móveis e imóveis durante o processo em análise. A forma mais adequada de escolher um elemento dentro de uma série é através da análise da mobilidade relativa durante a alteração hidrotermal ou por meio de estudos experimentais da solubilidade do elemento. Infelizmente, poucos estudos desta natureza são desenvolvidos em sistemas hidrotermais específicos, incluindo aqueles de formação de greisens. Em muitos casos, é assumido que elementos de baixa solubilidade são imóveis. A ordem usual de mobilidade dos elementos é dada por: $\{\mathrm{Zr}, \mathrm{Ti}\}<\{\mathrm{Y}$, $\mathrm{Ga}, \mathrm{Al}\}<\{\mathrm{Ce}, \mathrm{La}, \mathrm{Mg}\}<\{\mathrm{Mn}, \mathrm{Cr}, \mathrm{Fe}, \mathrm{Sc}, \mathrm{Cu}, \mathrm{Zn}, \mathrm{Pb}$, $\mathrm{V}, \mathrm{Ni}\}<\{\mathrm{Si}, \mathrm{Na}, \mathrm{K}, \mathrm{Ca}, \mathrm{Rb}, \mathrm{Sr}$ e $\mathrm{Ba}\}$.

Lentz \& Gregorie (1995) sugerem que o Al seja considerado o elemento menos móvel em sistemas hidrotermais contendo $\mathrm{F}$, já que, nesses casos, $\mathrm{Zr}$ e Ti podem se comportar como elementos móveis. Entretanto, o exame dos comportamentos de $\mathrm{Zr}$, Ti e Al, assim como dos demais elementos, levou à conclusão que o Ti se comportou como o elemento menos móvel durante os processos de greisenização estudados, sendo o mais adequado como referência para os cálculos de balanço de massa.

No presente estudo, foram efetuados cálculos de balanço de massa para as duas amostras de topázio- siderofilita-quartzo-greisen (intervalos 56,04-56,09 e 59,60-59,65; Tab. 4), bem como para o par topáziogranito/quartzo-topázio-siderofilita-greisen (Amostra F06Gr/56,47-56,62). Embora com algumas variações, o comportamento geral dessas amostras foi similar. A

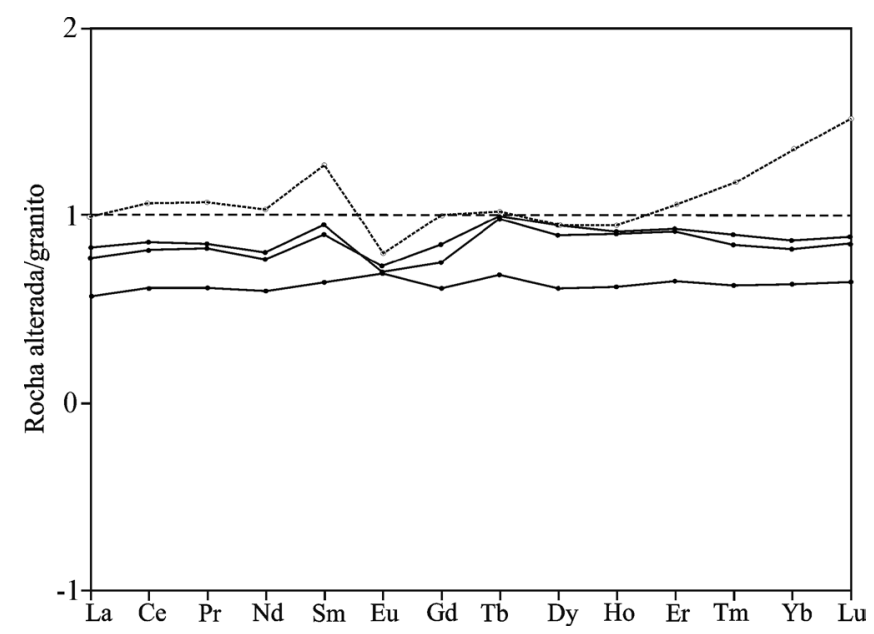

Figura 12 - Diagrama de distribuição de ETR das diversas amostras de greisen (linha contínua) e do granito-albitizado (linha pontilhada) em relação ao biotita-álcali feldspato-granito com topázio tomado como referência. A linha tracejada horizontal indica valores coincidentes entre granito e as amostras analisadas.

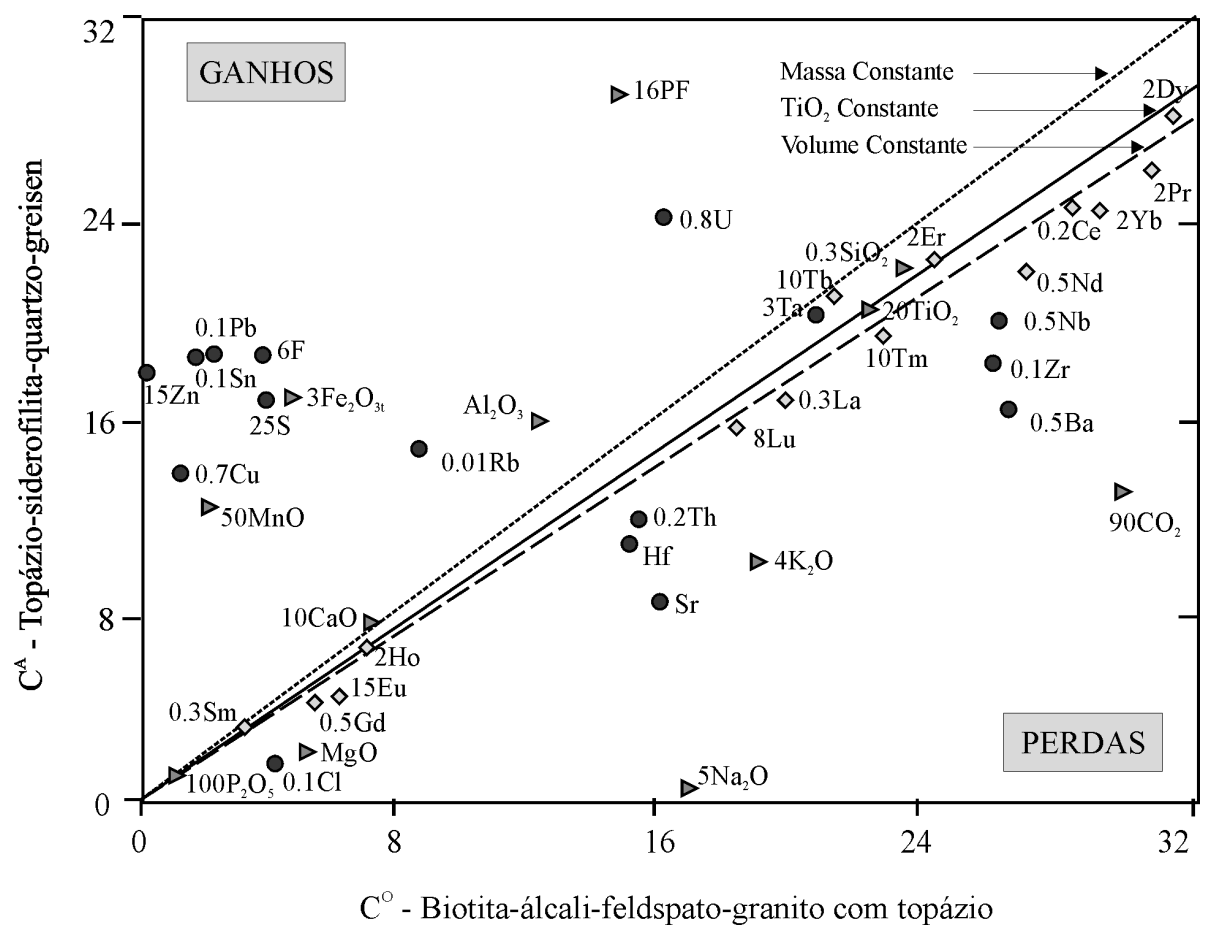

Figura 11 - Diagrama da isócona referente ao par biotita-álcali feldspatogranito com topázio e topázio-siderofilita-quartzo-greisen. As concentrações dos elementos maiores estão representadas em \% em peso, enquanto que os elementos menores estão em ppm. O reescalonamento das concentrações de elementos foi realizado para melhorar a distribuição de pontos no diagrama. 
Tabela 4 - Perdas e ganhos dos elementos maiores (em g/100g), elementos menores (em ppm/100g) e ETR (em ppm/100g) calculados a partir do método de Grant (1986) comparando o topázio-granito (Rocha original) com o topázio-siderofilita-quartzo-greisen (Rocha alterada).

\begin{tabular}{|c|c|c|c|c|c|c|c|c|}
\hline \multirow[b]{2}{*}{ Intervalo } & \multirow{2}{*}{$\begin{array}{c}\text { Toz-sdf-Kfs-gr } \\
49.28-49.33\end{array}$} & \multirow{2}{*}{$\begin{array}{c}\text { Toz-sdf-qtz-gs } \\
56,04-56,09\end{array}$} & \multicolumn{2}{|c|}{$\mathrm{TiO}_{2}$ constante } & \multicolumn{2}{|c|}{ Massa constante } & \multicolumn{2}{|c|}{ Volume constante } \\
\hline & & & & & & & & \\
\hline$\%$ em peso & $\mathrm{C}^{\mathrm{O}}$ & $\mathrm{C}^{\mathrm{A}}$ & $\Delta \mathrm{C}_{\mathrm{i}} / \mathrm{C}_{\mathrm{i}}^{\mathrm{O}}$ & $\Delta \mathrm{C}_{\mathrm{i}} / \mathrm{C}_{\mathrm{i}}^{\mathrm{O}}(\%)$ & $\Delta \mathrm{C}_{\mathrm{i}} / \mathrm{C}_{\mathrm{i}}^{\mathrm{O}}$ & $\Delta \mathrm{C}_{\mathrm{i}} / \mathrm{C}_{\mathrm{i}}^{\mathrm{O}}(\%)$ & $\Delta \mathrm{C}_{\mathrm{i}} / \mathrm{C}_{\mathrm{i}}^{\mathrm{O}}$ & $\Delta \mathrm{C}_{\mathrm{i}} / \mathrm{C}_{\mathrm{i}}^{\mathrm{O}}(\%)$ \\
\hline $\mathrm{SiO}_{2}$ & 76,87 & 72,16 & 0,03 & $3,26 \%$ & $-0,06$ & $-6,13 \%$ & 0,08 & $7,79 \%$ \\
\hline $\mathrm{TiO}_{2}$ & 0,11 & 0,10 & 0,00 & $0,00 \%$ & $-0,09$ & $-9,09 \%$ & 0,04 & $4,39 \%$ \\
\hline $\mathrm{Al}_{2} \mathrm{O}_{3}$ & 12,02 & 15,47 & 0,42 & $41,57 \%$ & 0,29 & $28,70 \%$ & 0,48 & $47,79 \%$ \\
\hline $\mathrm{Fe}_{2} \mathrm{O}_{3} \mathrm{t}$ & 1,51 & 5,48 & 2,99 & $299,21 \%$ & 2,63 & $262,91 \%$ & 3,17 & $316,73 \%$ \\
\hline $\mathrm{MgO}$ & 0,05 & 0,02 & $-0,56$ & $-56,00 \%$ & $-0,60$ & $-60,00 \%$ & $-0,54$ & $-54,07 \%$ \\
\hline $\mathrm{MnO}$ & 0,04 & 0,24 & 5,60 & $560,00 \%$ & 5,00 & $500,00 \%$ & 5,89 & $588,97 \%$ \\
\hline $\mathrm{CaO}$ & 0,69 & 0,72 & 0,15 & $14,78 \%$ & 0,04 & $4,35 \%$ & 0,20 & $19,82 \%$ \\
\hline $\mathrm{Na}_{2} \mathrm{O}$ & 3,31 & 0,09 & $-0,97$ & $-97,01 \%$ & $-0,97$ & $-97,28 \%$ & $-0,97$ & $-96,88 \%$ \\
\hline $\mathrm{K}_{2} \mathrm{O}$ & 4,67 & 2,42 & $-0,43$ & $-43,00 \%$ & $-0,48$ & $-48,18 \%$ & $-0,40$ & $-40,50 \%$ \\
\hline $\mathrm{P}_{2} \mathrm{O}_{5}$ & 0,01 & 0,01 & 0,10 & $10,00 \%$ & 0,00 & $0,00 \%$ & 0,15 & $14,83 \%$ \\
\hline $\mathrm{Zn}$ & 0,01 & 1,16 & 90,14 & $9014,29 \%$ & 81,86 & $8185,71 \%$ & 94,14 & $9414,39 \%$ \\
\hline $\mathrm{F}$ & 0,62 & 3,04 & 4,39 & $439,35 \%$ & 3,90 & $390,32 \%$ & 4,63 & $463,03 \%$ \\
\hline S & 0,15 & 0,65 & 3,77 & $376,67 \%$ & 3,33 & $333,33 \%$ & 3,98 & $397,59 \%$ \\
\hline $\mathrm{CO}_{2}$ & 0,33 & 0,14 & $-0,53$ & $-53,33 \%$ & $-0,58$ & $-57,58 \%$ & $-0,51$ & $-51,28 \%$ \\
\hline $\mathrm{PF}$ & 0,90 & 1,80 & 1,20 & $120,00 \%$ & 1,00 & $100,00 \%$ & 1,30 & $129,66 \%$ \\
\hline \multicolumn{9}{|c|}{ Elementos-traço (ppm) } \\
\hline $\mathrm{Ba}$ & 65,7 & 39,80 & $-0,33$ & $-33,36 \%$ & $-0,39$ & $-39,42 \%$ & $-0,30$ & $-30,44 \%$ \\
\hline $\mathrm{Rb}$ & 837,9 & 1434,40 & 0,88 & $88,31 \%$ & 0,71 & $71,19 \%$ & 0,97 & $96,58 \%$ \\
\hline $\mathrm{Sr}$ & 15,7 & 8,10 & $-0,43$ & $-43,25 \%$ & $-0,48$ & $-48,41 \%$ & $-0,41$ & $-40,76 \%$ \\
\hline $\mathrm{Zr}$ & 258,0 & 177,80 & $-0,24$ & $-24,19 \%$ & $-0,31$ & $-31,09 \%$ & $-0,21$ & $-20,87 \%$ \\
\hline Hf & 14,8 & 10,50 & $-0,22$ & $-21,96 \%$ & $-0,29$ & $-29,05 \%$ & $-0,19$ & $-18,53 \%$ \\
\hline Th & 75,5 & 57,10 & $-0,17$ & $-16,81 \%$ & $-0,24$ & $-24,37 \%$ & $-0,13$ & $-13,16 \%$ \\
\hline $\mathrm{U}$ & 19,8 & 29,80 & 0,66 & $65,56 \%$ & 0,51 & $50,51 \%$ & 0,73 & $72,82 \%$ \\
\hline $\mathrm{Nb}$ & 52,0 & 39,00 & $-0,18$ & $-17,50 \%$ & $-0,25$ & $-25,00 \%$ & $-0,14$ & $-13,88 \%$ \\
\hline $\mathrm{Ta}$ & 6,8 & 6,60 & 0,07 & $6,76 \%$ & $-0,03$ & $-2,94 \%$ & 0,11 & $11,45 \%$ \\
\hline $\mathrm{Sn}$ & 17,0 & 181,00 & 10,71 & $1071,18 \%$ & 9,65 & $964,71 \%$ & 11,23 & $1122,59 \%$ \\
\hline $\mathrm{Cu}$ & 1,7 & 19,00 & 11,29 & $1129,41 \%$ & 10,18 & $1017,65 \%$ & 11,83 & $1183,38 \%$ \\
\hline $\mathrm{Pb}$ & 22,3 & 181,70 & 7,96 & $796,28 \%$ & 7,15 & $714,80 \%$ & 8,36 & $835,62 \%$ \\
\hline $\mathrm{Cl}$ & 41,0 & 15,00 & $-0,60$ & $-59,76 \%$ & $-0,63$ & $-63,41 \%$ & $-0,58$ & $-57,99 \%$ \\
\hline \multicolumn{9}{|c|}{ Terras-raras (ppm) } \\
\hline $\mathrm{La}$ & 65,20 & 54,40 & $-0,08$ & $-8,22 \%$ & $-0,17$ & $-16,56 \%$ & $-0,04$ & $-4,19 \%$ \\
\hline $\mathrm{Ce}$ & 140,90 & 120,90 & $-0,06$ & $-5,61 \%$ & $-0,14$ & $-14,19 \%$ & $-0,01$ & $-1,47 \%$ \\
\hline $\operatorname{Pr}$ & 15,29 & 12,81 & $-0,08$ & $-7,84 \%$ & $-0,16$ & $-16,22 \%$ & $-0,04$ & $-3,80 \%$ \\
\hline $\mathrm{Nd}$ & 53,70 & 43,10 & $-0,12$ & $-11,71 \%$ & $-0,20$ & $-19,74 \%$ & $-0,08$ & $-7,84 \%$ \\
\hline $\mathrm{Sm}$ & 10,60 & 10,00 & 0,04 & $3,77 \%$ & $-0,06$ & $-5,66 \%$ & 0,08 & $8,33 \%$ \\
\hline $\mathrm{Eu}$ & 0,40 & 0,28 & $-0,23$ & $-23,00 \%$ & $-0,30$ & $-30,00 \%$ & $-0,20$ & $-19,62 \%$ \\
\hline $\mathrm{Gd}$ & 10,58 & 7,91 & $-0,18$ & $-17,76 \%$ & $-0,25$ & $-25,24 \%$ & $-0,14$ & $-14,15 \%$ \\
\hline $\mathrm{Tb}$ & 2,10 & 2,05 & 0,07 & $7,38 \%$ & $-0,02$ & $-2,38 \%$ & 0,12 & $12,09 \%$ \\
\hline Dy & 15,63 & 13,93 & $-0,02$ & $-1,96 \%$ & $-0,11$ & $-10,88 \%$ & 0,02 & $2,34 \%$ \\
\hline Ho & 3,42 & 3,11 & 0,00 & $0,03 \%$ & $-0,09$ & $-9,06 \%$ & 0,04 & $4,42 \%$ \\
\hline $\mathrm{Er}$ & 12,04 & 11,02 & 0,01 & $0,68 \%$ & $-0,08$ & $-8,47 \%$ & 0,05 & $5,10 \%$ \\
\hline $\mathrm{Tm}$ & 2,25 & 1,89 & $-0,08$ & $-7,60 \%$ & $-0,16$ & $-16,00 \%$ & $-0,04$ & $-3,54 \%$ \\
\hline $\mathrm{Yb}$ & 14,53 & 12,00 & $-0,09$ & $-9,15 \%$ & $-0,17$ & $-17,41 \%$ & $-0,05$ & $-5,17 \%$ \\
\hline $\mathrm{Lu}$ & 2,25 & 1,90 & $-0,07$ & $-7,11 \%$ & $-0,16$ & $-15,56 \%$ & $-0,03$ & $-3,03 \%$ \\
\hline
\end{tabular}




\begin{tabular}{l|l|l|l|l|c|c|c}
\hline & & & & & \multicolumn{3}{|c}{ Isóconas } \\
\hline & & & & & TiO cte & Massa cte & Volume cte \\
\hline $\mathrm{d}^{\mathrm{O}}\left(\mathrm{g} / \mathrm{cm}^{3}\right)$ & 2,63 & & $\mathrm{M}^{\mathrm{O}} / \mathrm{M}^{\mathrm{A}}=\left(\mathrm{C}^{\mathrm{A}} \mathrm{Ti2}_{2} / \mathrm{C}^{\mathrm{O}}{ }_{\mathrm{TiO2}}\right)$ & & 0,91 & 1 & 0,87 \\
\hline $\mathrm{d}^{\mathrm{A}}\left(\mathrm{g} / \mathrm{cm}^{3}\right)$ & 3,02 & & $\mathrm{C}^{\mathrm{A}}=\left(\mathrm{M}^{\mathrm{O}} / \mathrm{M}^{\mathrm{A}}\right) \mathrm{C}^{\mathrm{O}}$ & & $\mathrm{C}^{\mathrm{A}}=0,91 \mathrm{C}^{\mathrm{O}}$ & $\mathrm{C}^{\mathrm{A}}=\mathrm{C}^{\mathrm{O}}$ & $\mathrm{C}^{\mathrm{A}}=0,87 \mathrm{C}^{\mathrm{O}}$ \\
\hline$\Delta \mathrm{M}_{\mathrm{i}} / \mathrm{M}^{\mathrm{O}}=\left(\mathrm{M}^{\mathrm{A}} / \mathrm{M}^{\mathrm{O}}\right) \mathrm{C}_{\mathrm{i}}^{\mathrm{A}}-\mathrm{C}_{\mathrm{i}}^{\mathrm{O}}$ & & $\mathrm{V}^{\mathrm{A}} / \mathrm{V}^{\mathrm{O}}=\left(\mathrm{M}^{\mathrm{A}} / \mathrm{M}^{\mathrm{O}}\right)\left(\mathrm{d}^{\mathrm{O}} / \mathrm{d}^{\mathrm{A}}\right)$ & & 0,96 & 0,87 & 1,00 \\
\hline$\Delta \mathrm{C}_{\mathrm{i}} / \mathrm{C}_{\mathrm{i}}^{\mathrm{O}}=\left(\mathrm{M}^{\mathrm{A}} / \mathrm{M}^{\mathrm{O}}\right)\left(\mathrm{C}_{\mathrm{i}}^{\mathrm{A}} / \mathrm{C}_{\mathrm{i}}^{\mathrm{O}}\right)-1$ & & $\Delta \mathrm{V}=\left(\mathrm{V}^{\mathrm{A}} / \mathrm{V}^{\mathrm{O}}-1\right.$ & & $-4,21 \%$ & $-12,91 \%$ & $0,00 \%$ \\
\hline
\end{tabular}

discussão detalhada sobre cada amostra pode ser encontrada em Feio (2007). Para ilustrar os efeitos de ganho e perda de massa, foi seleciondo o par topázio-granito/ topázio-siderofilita-quartzo-greisen (intervalo do greisen 56,04-56,09; Tab. 4), pois esse par é considerado bastante representativo do conjunto estudado.

Alteração - granito $\rightarrow$ topázio-siderofilita-
quartzo-greisen
(Par de amostras F06Gr/56,04-56,09- F06Gr/49.2849.33)

Os cálculos de mobilidade geoquímica dos elementos durante a formação do topázio-siderofilitaquartzo-greisen (produto final da alteração) a partir do biotita-álcali feldspato-granito com topázio (considerado como a rocha original) é mostrado na tabela 4.

A análise do diagrama binário isocônico de Grant (1986) mostra que a maioria dos ETR mostra excelente alinhamento, o qual quase se superpõe com a isócona de volume constante. A escolha das isóconas de $\mathrm{TiO}_{2}$ ou de massa constante implicaria uma diminuição, respectivamente, de 4,5 e 13,2\% no volume do granito e seriam, a princípio, menos adequadas como referência para os cálculos de balanço de massa, muito embora a isócona de $\mathrm{TiO}_{2}$ constante seja quase coincidente com a de volume constante. Os pontos mencionados fortalecem a opção pelo uso de tal isócona como referência para a avaliação de perdas e ganhos dos elementos durante a formação do topázio-siderofilita-quartzo-greisen em discussão.

Comparando o comportamento dos diferentes elementos com a isócona de volume constante $\left(\mathrm{F}_{\mathrm{v}}=1\right)$ constata-se que o processo de greisenização ocasionou um aumento de $13 \%$ na massa original do granito, para um mesmo volume de rocha, o que justifica a maior densidade do greisen. Os componentes menos móveis durante a greisenização foram $\mathrm{SiO}_{2}, \mathrm{TiO}_{2}$ e ETR, a exceção do Eu (Fig. 11). Os componentes que foram adicionados em quantidades expressivas foram, em ordem crescente de ganho relativo, $\mathrm{Fe}_{2} \mathrm{O}_{3 \mathrm{t}}, \mathrm{S}, \mathrm{F}$ e $\mathrm{Zn}$. Por outro lado, $\mathrm{Na}_{2} \mathrm{O}, \mathrm{MgO}, \mathrm{CO}_{2}$ e $\mathrm{K}_{2} \mathrm{O}$ foram os elementos que tiveram seus conteúdos mais reduzidos. Com exceção de $\mathrm{Cu}, \mathrm{Sn}, \mathrm{Pb}, \mathrm{Ta}, \mathrm{Rb}$ e U, que enriqueceram no sentido da greisenização e excluídos os ETR, os demais elementos-traço empobreceram. $\mathrm{Fe}_{\mathrm{t}}, \mathrm{Zn}, \mathrm{F}, \mathrm{S}, \mathrm{Sn}, \mathrm{Cu}$ e $\mathrm{Pb}$ foram os principais elementos responsáveis pelo aumento de massa no processo de formação deste topázio-siderofilita-quartzo-greisen.
Os elementos terras raras (ETR) revelaram pouca mobilidade e forneceram padrões muito similares aos dos granitos. De modo geral, constataram-se nos greisens teores semelhantes ou ligeiramente inferiores aos dos granitos (Tab. 4, Fig. 12). A exceção é o quartzo-topázio-siderofilita-greisen, que apresentou ligeiro empobrecimento em todos os ETR, tanto leves quanto pesados (Fig. 12). O granito albitizado revela enriquecimento relativo em ETR pesados e quase imobilidade dos ETR leves.

DISCUSSÕES E CONCLUSÕES Os processos de transformação hidrotermal no sistema granito-greisen dependem da composição mineralógica primária do granito, das características do fluido, incluindo aí a sua natureza e volume, e de parâmetros como temperatura, pressão e fugacidade de oxigênio. No âmbito da Província Estanífera de Pitinga, a greisenização provocou alteração mineralógica e textural radical do biotita-álcali feldspato-granito com topázio, resultando na formação do granito greisenizado e greisens, os últimos mineralizados em estanho e, subordinadamente, em zinco.

Os greisens, segundo cálculos de balanço de massa, apresentaram aumento de $8-13 \%$ de massa em relação ao granito, o que justifica a sua maior densidade comparativa, admitindo-se um processo de transformação isovolumétrico, Os componentes que tiveram maior massa adicionada foram $\mathrm{Zn}, \mathrm{S}, \mathrm{Cu}, \mathrm{Fe}_{2} \mathrm{O}_{3}, \mathrm{MnO}, \mathrm{Pb}, \mathrm{Sn}$ e F, ao passo que $\mathrm{Na}_{2} \mathrm{O}, \mathrm{K}_{2} \mathrm{O}, \mathrm{CO}_{2}, \mathrm{Eu}$, Ba e Sr tiverem seus conteúdos expressivamente reduzidos.

As variações químicas observadas ao longo do processo de greisenização são resultantes da desestabilização de minerais do topázio-granito e da sua gradual substituição pela paragênese mineral dos greisens. A remoção de $\mathrm{Na}$ e K, a adição de $\mathrm{Fe}$, Sn e S, e o aumento nas concentrações de $\mathrm{F}$ e de componentes voláteis são os principais marcadores geoquímicos do processo de greisenização avançada do granito. Estas mudanças químicas refletem a desestabilização do feldspato alcalino pertítico do granito e sua gradual substituição no greisen por agregados de siderofilita e topázio. $\mathrm{O} F$ e $\mathrm{Al}_{2} \mathrm{O}_{3}$ são fixados nas micas e no topázio neoformados. $\mathrm{O} \mathrm{Fe}$ total adicionado à rocha foi incorporado à siderofilita e aos sulfetos. $\mathrm{O}$ teor de $\mathrm{Rb}$ aumenta no greisen, devido à sua retenção na estrutura da siderofilita, enquanto $\mathrm{Ba}$ e parte do Sr são removidos devido à desestabilização dos feldspatos.

Os elementos terras raras (ETR) revelaram pouca mobilidade e forneceram padrões muito simi- 
lares aos dos granitos. De modo geral, constataram-se nos greisens teores semelhantes ou ligeiramente inferiores aos dos granitos (Fig. 10), o que demonstra que os fluidos responsáveis pelo processo de greisenização não foram capazes de remobilizar os elementos terrasraras do protólito granítico, de modo expressivo. Esse comportamento é similar ao observado nos greisens da área Guinho-Baixão (Borges 2002) e nos epissienitos sódicos micáceos da área Queixada (Costi et al. 2002), ambas do pluton Água Boa de Pitinga. Difere, no entanto, do que se constatou nos epissienitos sódicos desta última área, nos quais a mobilidade dos ETR foi muito acentuada (Costi et al. 2002).

Em linhas gerais, os processos de greisenização em estudo são similares aqueles responsáveis pela geração dos greisens com topázio e siderofilita associados ao granito rapakivi de Pitinga (Borges 2002). Admitese que os fluidos formadores dos greisens seriam fluidos residuais ricos em $\mathrm{F}, \mathrm{Sn}, \mathrm{Zn}$ e S , derivados de granito evoluído do tipo A. Tais fluidos circularam através de condutos existentes no topo do corpo granítico e co- mandaram os processos de greisenização, que afetaram as diferentes variedades de granito do corpo Água Boa (topázio-granito, biotita-granito e granito rapakivi). Fluidos ainda mais tardios e de mais baixa temperatura, pobres em $\mathrm{F}$ e ricos em $\mathrm{SiO}_{2}$ e $\mathrm{Zn}$ geraram os veios de quartzo, que cortam os greisens.

Agradecimentos Agradecemos aos pesquisadores do Grupo de Pesquisa Petrologia de Granitóides (GPPGCGUFPA) pelo apoio nas diversas etapas deste traba1ho; aos Geólogos do Grupo Paranapanema S/A pela liberação dos testemunhos de sondagem e apoio logístico nas etapas de campo; ao químico Natálino Valente do CG-UFPA, pelas análises de $\mathrm{FeO}$; à $\mathrm{ADIMB}$ e ao CNPQ pela concessão da bolsa de mestrado da primeira autora; ao Programa de Pós-graduação em Geoquímica e Petrologia juntamente com o Centro de Geociências (CG-UFPA) pelo suporte técnico; ao CNPq pelo apoio ao desenvolvimento da pesquisa (55.0739/01-7, 476075/03-3). Este artigo é uma contribuição ao projeto IGCP-510.

\section{Referências}

Almeida F.F.M., Hasui Y., Brito Neves B.B., Fuck R.A. 1981. Brazilian structural Provinces: An introduction. Earth Sciences Reviews, 17:1-29.

Almeida M.E. 2006. Evolução Geológica da porção centrosul do escudo das Guianas com base no estudo Geoquímico, Geocronológico (Evaporação de b e U-Pb ID-TIMS em zircão) e isotópico (Nd-P) dos granitóides Paleoproterozóicos do sudeste de Roraima. Tese de Doutoramento, Instituto de Geociências, Universidade Federal do Pará, 227p.

Araújo Neto H., Moreira H.L. 1976. Projeto Estanho Abonari. Manaus, MME/DNPM/CPRM, Relatório final, 232p.

Borges R.M.K. 1997. Petrografia e química mineral dos greisens associados ao Granito Água Boa - Mina Pitinga (AM):Um estudo dos processos de formação de greisens. Dissertação de Mestrado, Instituto de Geociências, Universidade Federal do Pará, 190p.

Borges R.M.K. 2002. Greisens e epissienitos potássicos associados ao Granito Água Boa, Pitinga (AM): Um estudo dos processos hidrotermais geradores de mineralizações estaniferas. Tese de Doutoramento, Instituto de Geociências, Universidade Federal do Pará, 383p.

Collins W.J., Beams S.D., White A.J.R., Chappell B.W. 1982. Nature and origin of A-type granites with particular reference to southeastern Australia. Contributions to Mineralogy and Petrology, 80(2):189-200.

Costi H.T., Dall'Agnol R., Moura C.A.V. 2000. Geology and $\mathrm{Pb}-\mathrm{Pb}$ Geochronology of Paleoproterozoic Volcanic and Granitic rocks of Pitinga Province, Amazonian Craton, Northern Brazil. International Geology Reviews, 42:832-849.

Costi H.T., Dall'Agnol R., Borges R.M.K., Minuzzi O.R.R., Teixeira J.T. 2002. Tin-Bearing Sodic Episyenites Associated with the Proterozoic, A-Type Água Boa Granite, Pitinga Mine, Amazonian Craton, Brazil. Gondwana Re- search., 5:435-451.

Costi H.T., Borges R.M.K., Dall'Agnol R. 2005. Depósitos de estanho da Mina Pitinga, Estado do Amazonas. In: O.J. Marini, E.T. Queiroz, B.W. Ramos (eds.) Caracterização de depósitos minerais em distritos mineiros da Amazônia. DNPM/CT-mineral FINEP/ADIMB, p. 391475.

Dall'Agnol R., Teixeira N.P., Magalhães M.S. 1993. Diagnostic features of the Tin-specialized anorogenic granites of the Eastern Amazonian Region. Anais Acadêmia Brasileira de Ciências, 65:33-50.

Daoud W.K. 1988. Granitos Estaniferos de Pitinga, Amazonas: Contexto Geológico e Depósitos Minerais Associados. Dissertação de Mestrado, Instituto de Geociências, Universidade de Brasília, 194p.

Daoud W.K. \& Antonietto Jr. A. 1985. Geologia do Granito Água Boa, Pitinga, AM. In: SBG, Simp. Geol. Amazônia, 2, Anais, v. 3, p.17-33.

Evensen N.M., Hamilton P.J., O'Nions R.K. 1978. Rareearth abundances in chondritic meteorites. Geochimica et Cosmochimica Acta, 42(8):1199-1212.

Feio G.R.L. 2007. Petrografia e Geoquímica dos greisens associados ao topázio-granito do pluton Água Boa, Provincia Estanifera de Pitinga (AM). Dissertação de Mestrado, Instituto de Geociências, Universidade Federal do Pará, 132p.

Ferron J.M.T.M. 2006. Geologia regional, Geoquímica e Geocronologia $\mathrm{Pb}-\mathrm{Pb}$ de rochas graniticas e vulcânicas paleoproterozóicas da Província Pitiga, Cráton Amazônico. Tese de Doutoramento, Instituto de Geociências, Universidade Federal do Rio Grande do Sul, 331p.

Ferron J.M.T.M., Neto A.C.B., Lima E.F., Costi H.T., Moura, C.A.V., Prado M., Pierosan R. 2006. Geologia e Geocronologia $\mathrm{Pb}-\mathrm{Pb}$ de rochas graníticas e vulcânicas ácidas a intermediárias Paleproterozóicas da Província Pitinga, 
Craton Amazônico. Revista Brasileira de Geociências, 36(3):499-512.

Gibbs A.K. \& Barron C. 1983. The Guiana shield reviewed. Episodes, 6:7-14.

Grant J.A. 1986. The isocon diagram - A simple solution to Gresens' equation for metassomatic alteration. Economic Geology, 81:1976-1982.

Gresens R.L. 1967. Composition-volume relationshis of metasomatism. Chemical Geology, 2:47-65.

Haapala I. 1997. Magmatic and postmagmatic processes in tin-mineralized granites: topaz bearing leucogranite in the Eurajoki Rapakivi Granite stock, Finland. Journal of Petrology, 12:1645-1649.

Horbe M.A., Horbe A.C., Teixeira J.T., Costi H.T. 1985. Granito Madeira: Petrologia, Petroquímica e Mineralizações. In: SBG, Simp. Geol. Amazônia, 2, Anais, vol.3, p.284-320.

Horbe M.A., Horbe A.C., Costi H.T., Teixeira J.T. 1991. Geochemical characteristics of cryolite-tin-bearing granites from Pitinga Mine, northwestern Brazil - A review. Journal of Geochemical Exploration, 40:227-249.

Kuhne R., Wasternack J., Schulze H. 1972. Post-magmatische Metasomatose im Endo-Exokontakt der jüngeren postkinematischen Granite des Erzgebirges. Geologie, 21:494-520.

Leite Jr. W.B. 2002. A Suite Intrusiva Santa Clara (RO) e a mineralização primária polimetálica $(\mathrm{Sn}, \mathrm{W}, \mathrm{Nb}, \mathrm{Ta}, \mathrm{Zn}$, $\mathrm{Cu}$ e $\mathrm{Pb}$ ) associada. Tese de Doutoramento, Instituto de Geociências, Universidade de São Paulo, 305p.

Lenharo S.L.R. 1998. Evolução magmática e modelo metalogenético dos granitos mineralizados da região de Pitinga, Amazonas, Brasil. Tese de Doutoramento, Escola Técnica da Universidade de São Paulo, Universidade de São Paulo, 290 p.

Lenharo S.L.R., Moura M.A., Botelho N.F. 2002. Petrogenetic and mineralization processes in Paleo to Mesoproterozoic rapakivi granites: examples from Pitinga and Goiás, Brazil. Precambrian Research, 119:277-299.

Lentz D.R. \& Gregoire C. 1995. Petrology and mass-balance constraints on major, trace, and rare-earth-element mobility in porphyrygreisen alteration associated with the epizonal True Hill granite, southwestern New Brunswick, Canada. Journal of Geochemical Exploration, 52:303-33.

Loiselle M.C. \& Wones D.R. 1979. Characteristics and origin of anorogenic granites. Geological Society American Abstract Program, 11:468.

Santos J.O.S., Hartmann L.A., MCnaughton N.J., Fletchu
I.R. 2002. Timing of mafic magmatism in the Tapajós Province (Brazil) and implications for the evolution $\mathrm{f}$ the Amazon Craton: evidence from baddeleyite and zircon U-Pb SHRIMP geocrhronology. Journal of South American Earth Sciences, 15:409-429.

Shcherba G.N. 1970. Greisens. International Geology Review, 12:114-150, 239-259.

Smith J.V. \& Brown W.L. (Eds.) 1988. Feldspar minerals. Berlin, Spring-Verlag, 828p.

Streckeisen A. 1976. To each plutonic rocks its proper name. Earth Science Reviews, 12:1-33.

Tassinari C.C.G. \& Macambira M.A. 2004. Evolução Tectônica do Craton Amazônico. In: V. Mantesso-neto, A. Bartorelli, C.D.R. Carneiro, B.B. de Brito Neves (eds.) Geologia do Continente Sul Americano: Evolução da obra de F.F.M. de Ameida. BECA, São Paulo, p. 471486.

Taylor R.P. \& Fryer B.J. 1983. Rare-earth lithogeochemistry of granitoid mineral deposits. CIM Bull., 76:74-84.

Teixeira N.P. 1999. Contribuição ao estudo das rochas granitóides e mineralizações associadas da Suite Intrusiva Velho Guilherme, Província Estanífera do Sul do Pará. Tese de Doutoramento, Instituto de Geociências, Universidade de São Paulo, 508p.

Tischendorf G. 1977. Geochemical and Petrographic characteristics of silic magmatic rocks associated with rareelements mineralization. In: M.S. Stemprok, L. Burnol, G. Tischendorf (eds.) Metallization associated with acid magmatism. Prague, Geological Survey, p. 41-96.

Tuttle O.F. \& Bowen N.L. 1958. Origin of granite in the light of experimental studies in the system $\mathrm{NaAl} \mathrm{Si}_{3} \mathrm{O}_{8}$ - $\mathrm{KAlSi}_{3} \mathrm{O}_{8}-\mathrm{SiO}_{2}-\mathrm{H}_{2} \mathrm{O}$. Geological Society of America, 74:153p.

Valério C. da S. 2006. Magmatismo Paleoproterozóico do extremo sul do Escudo das Guianas, Município de Presidente Figueiredo (AM): Geologia, geoquímica e geocronologia $\mathrm{Pb}-\mathrm{Pb}$. Dissertação de Mestrado, Universidade Federal do Amazonas, 215p.

Whalen J.B., Currie K.L., Chappell B.W. 1987. A-type granites: Geochemical characteristics, discrimination and petrogenesis. Contributions to Mineralogy and Petrology, 95:407-419.

Manuscrito ID 8169

Submetido em 12 de maio de 2007 Aceito em 15 de setembro de 2007 Sistema Eletrônico de Submissão 